\title{
28 Research Square \\ Kefir Ameliorates Specific Physiological and Behavioural Impairments in a Mouse Model of Autism Spectrum Disorder
}

\section{Marcel van de Wouw}

University College Cork National University of Ireland

\section{Giulia MD Vigano}

University of Milan

Joshua M Lyte

University College Cork National University of Ireland

Marcus Boehme

University College Cork National University of Ireland

Andreu Gual

Universitat Rovira i Virgili

Aaron M Walsh

Teagasc Food Research Centre Moorepark

Gerard Clarke

University College Cork National University of Ireland

Paul D. Cotter

Teagasc Food Research Centre Moorepark

Timothy G. Dinan

University College Cork National University of Ireland John F. Cryan ( $\sim$ j.cryan@ucc.ie)

University College Cork National University of Ireland https://orcid.org/0000-0001-5887-2723

\section{Research}

Keywords: Kefir, Mouse, Behaviour, Immunity, Serotonin, Stress, Gut, Monocyte, T regulatory cell

Posted Date: December 23rd, 2019

DOI: https://doi.org/10.21203/rs.2.19433/v1

License: (c) (1) This work is licensed under a Creative Commons Attribution 4.0 International License.

Read Full License 


\section{Abstract}

Autism spectrum disorders (ASD) is one of the most severe developmental disorders, affecting on average 1 in 150 children worldwide. There are limited treatment options for ASD symptoms and there is therefore a great need for more effective strategies to improve quality of life in ASD subjects. The gut microbiome has recently emerged as a therapeutic target in ASD. A novel modulator of the gut microbiome, the traditionally fermented milk drink kefir, has recently been shown to modulate the microbiota and decrease repetitive behaviour, one of the hallmarks of ASD. As such, we hypothesised that kefir could ameliorate the behavioural phenotype of ASD in the animal model of ASD; the BTBR T + Itpr3 tf / J mouse strain. Adult mice were administered either kefir (UK4) or milk control for 3 weeks as treatment lead-in, after which they were assessed for their behavioural phenotype using a battery of tests. In addition, we assessed systemic immunity by flow cytometry. We found that kefir decreased repetitive behaviour. Furthermore, kefir prolonged stress-induced increases in corticosterone 60 minutes post-stress, which was accompanied by an ameliorated innate immune response as measured by LY6C hi monocyte levels. Furthermore, kefir increased the levels of anti-inflammatory Treg cells in mesenteric lymph nodes. Altogether, our data show that kefir modulates peripheral immunity in an anti-inflammatory manner and can ameliorate specific ASD behavioural dysfunctions, indicating that kefir supplementation might prove a viable strategy in improving quality of life in ASD subjects.

\section{Background}

Autism spectrum disorder (ASD) is one of the most severe neurodevelopmental conditions, affecting on average 1 in 150 children worldwide (Lyall et al. 2017). ASD is hallmarked by impaired social communication skills and enhanced engagement in repetitive behaviours, frequently co-occurring with intellectual disability (Association 2013). In addition, there is a growing body of evidence showing that ASD is associated with substantial differences in gut microbiota composition, as well as symptoms of gastrointestinal dysfunction, such as altered bowel habits, bloating, abdominal pain and increased intestinal permeability (D'Eufemia et al. 1996, De Angelis et al. 2013, Kang et al. 2013, McElhanon et al. 2014, Tomova et al. 2015, Luna et al. 2017). Overall, these findings indicate a disturbed communication between the gastrointestinal microbiota and the brain, in what has been coined the microbiota-gut-brain axis (Rhee et al. 2009, Collins et al. 2012, Cryan et al. 2012, Mayer et al. 2014, Foster et al. 2017, Cryan et al. 2019, Sherwin et al. 2019). As such, the gut microbiome is increasingly being recognised as an important novel player and therapeutic target in ASD (Vuong et al. 2017). This is additionally supported by a study showing that the transplantation of standardised human gut microbiota to ASD-diagnosed children results in improved gastrointestinal functionality and reduced behavioural ASD scoring (Kang et al. 2017).

Preclinical research has proven crucial in finding microbiota-based therapeutics for ASD (Hsiao et al. 2013, Kumar et al. 2016). A preclinical animal model often used to study ASD is the BTBR T ${ }^{+} \mathrm{Itpr}^{\mathrm{tf}} / \mathrm{J}$ mouse strain. This mouse model, similarly to humans, shows robust deficits in social interaction, increased repetitive behaviours and an abnormal gut microbiota accompanied with symptoms of 
gastrointestinal dysfunction (Moy et al. 2007, Golubeva et al. 2017). A novel modulator of the microbiotagut-brain axis is the traditionally fermented milk drink kefir (Bourrie et al. 2016, Aslam et al. 2018). Previous work from our lab has demonstrated that kefir is able to modulate the microbiota and decrease repetitive behaviour in the most commonly used C57BL/6 mouse strain (Van de Wouw et al.

Unpublished). In addition, a probiotic containing kefir-derived bacteria ameliorates lipopolysaccharideinduced changes in immune responses and depression- and anxiety-like behaviours (Murray et al. 2019). As such, we aimed to investigate if kefir supplementation could ameliorate some of the ASD deficits seen in the BTBR $\mathrm{T}^{+} \mathrm{Itpr}^{\mathrm{tf}} / \mathrm{J}$ mouse strain, such as social interaction, repetitive behaviour and gastrointestinal function. Furthermore, we aimed to interrogate the peripheral immune system as a key mediator of kefirinduced gut-brain communication (Lowry et al. 2016, Langgartner et al. 2018).

\section{Methodology}

Animals

This study used male BTBR $\mathrm{T}^{+} \mathrm{Itpr} 3^{\mathrm{tf}} / \mathrm{J}$ mice (5-6 months of age at the start of the experiment, inhouse bred). Treatment groups were divided into Milk control $(n=11)$, and Kefir UK4 $(n=9)$. Animals were housed in groups of $2-3$. The holding room had a temperature of $21 \pm 1{ }^{\circ} \mathrm{C}$ and humidity of $55 \pm 10 \%$ with a 12-hour light/dark cycle (lights on at 7:00 am). Food and drinking water were provided ad libitum throughout the study. Bodyweight was monitored on a weekly basis. All experiments were conducted under the project authorization license B100/3774 in accordance with the European Directive 86/609/EEC and the Recommendation 2007/526/65/EC and were approved by the Animal Experimentation Ethics Committee of University College Cork. All efforts were made to reduce the number of animals used and to minimise the suffering of the animals.

Experimental timeline and behavioural testing

Animals received daily kefir administration by oral gavage for three weeks prior to the assessment of their behavioural phenotype using various tests, which were formed in order of least stressful to most stressful to reduce the likelihood of prior behavioural tests influencing subsequent ones (Fig. 1). In addition, there was a minimum of 36-hours between tests. The order of testing was as follows: 1) Open field test, 2) Marble burying test, 3) Assesment of self-grooming, 4) 3-Chamber social interaction test, 5) Elevated plus maze, 6) Tail-suspension test, 7) Stress-induced hyperthermia test, 8) Intestinal motility test, 9) FITCDextran intestinal permeability test, 10) Fear conditioning, 11) Forced swim test. At the end of the study, animals were sacrificed by decapitation.

Kefir culturing and administration

Kefir UK4 was chosen based on its ability to decrease repetitive behaviour and modulate adaptive immunity (van de Wouw et al., unpublished). These experiments were performed in a relatively similar time frame as the preparation that was previously described. Kefir grains were cultured in whole milk ( $2 \%$ $\mathrm{w} / \mathrm{v}$ ) at $25^{\circ} \mathrm{C}$ and milk was renewed every 24 hours using a sterile Buchner funnel and sterile Duran 
bottle, as previously described (Dobson et al. 2011, Walsh et al. 2016). Grains were rinsed with sterile deionised water prior to the renewal of milk. The fermented milk (i.e. kefir) collected after the culturing, or milk control, were administered to the mice within one hour by oral gavage $(0.2 \mathrm{~mL})$. Daily kefir administration was performed after the behavioural test, if one was performed that day, between 4.00 and 7.00 p.m.

\section{Open field test}

Mice were assessed for locomotor activity and response to a novel environment in the open field test, which was conducted as previously described (Burokas et al. 2017). Animals were placed in an open arena $(40 \times 32 \times 24 \mathrm{~cm}, \mathrm{~L} \times \mathrm{W} \times \mathrm{H})$ and were allowed to explore the arena for 10 minutes. Animals were habituated to the room 30 minutes prior to the test. Testing was performed under dim light (60 lux). The open field test box was cleaned with 70\% ethanol in-between animals. Experiments were videotaped using a ceiling camera and were analysed for time spent in the virtual centre zone (defined as $50 \%$ away from the edges) and total distance travelled using Ethovision version 13 software (Noldus).

Marble burying test

Mice were tested for repetitive and anxiety-like behaviour with the marble burying test, which was conducted as previously described (Burokas et al. 2017). Animals were individually placed in a novel Plexiglas cage $(35 \times 28 \times 18.5 \mathrm{~cm}, \mathrm{~L} \times \mathrm{W} \times \mathrm{H})$, which was filled with sawdust $(5 \mathrm{~cm})$ and had 20 equally spread marbles placed on top ( $5 \times 4$ rows). After mice had spent 20 minutes in the cage, the number of buried marbles was counted by two researchers and averaged. A buried marble was defined as $2 / 3$ of the marble not being visible anymore. In addition, all experiments were videotaped using a ceiling camera and the time the mice showed burying behaviour was scored. Sawdust was renewed, and marbles cleaned with $70 \%$ ethanol in-between animals.

Self-grooming test

Mice were tested for repetitive and anxiety-like behaviour by assessing self-grooming. Animals were individually placed in a $250 \mathrm{~mL}$ glass beaker for 30 minutes. A hard-plastic cover was put on the beaker to prevent the mice from escaping and paper covers were put between the beakers containing test mice to block visual contact. This test was performed under dim light (60 lux). All experiments were videotaped using a camera and scored for grooming time. Beakers and the hard-plastic cover were cleaned after each test mouse with $70 \%$ ethanol and left to dry for a few minutes.

\section{3-Chamber social interaction test}

The three-chamber sociability test was used to assess social preference and recognition and was conducted as previously described (Desbonnet et al. 2014). The testing apparatus was a threechambered, rectangular box. The dividing walls between each chamber $(20 \times 40 \times 22 \mathrm{~cm}, \mathrm{~L} \times \mathrm{W} \times \mathrm{H})$ had small circular openings ( $5 \mathrm{~cm}$ diameter), allowing for access to all chambers. The two outer chambers contained wire cup-like cages (10 cm bottom diameter, $13 \mathrm{~cm}$ height), allowing for auditory, olfactory and 
visual, but not physical contact. The test consisted of 10-minute three phases: 1) Habituation, 2) Social preference, 3) Social recognition. In the first phase (Habituation), mice were allowed to explore the entire box with both wire cup-like cages left empty to allow for habituation to the novel environment. In the second phase (Social preference), one wire cup-like cage contained a novel, age-matched, conspecific, male mouse, whereas the other cage contained an object (rubber duckie). In the third phase (Social recognition), the mouse of the previous trial was left in the wire cup-like cage (Familiar mouse), while the object was replaced with a conspecific mouse (Novel mouse). The test mouse was held in the middle chamber while the conspecific mouse and object were placed in the cup wire-like cages. The location of the conspecific mice and object were systemically altered in-between test mice. The three-chamber test apparatus and wire cup-like cages were cleaned with $70 \%$ ethanol after each test mouse and left to dry for a few minutes. To reduce potential anxiogenic factors, all mice were habituated to the testing room 40 minutes before the test, the floor of the testing arena was covered with sawdust and testing was performed under dim light (60 lux). All experiments were videotaped using a ceiling camera and were scored blinded for the time interacted with the wire cup-like cages. The discrimination index was calculated as follows: Time spent interacting with object or mouse / Total time spent interacting ${ }^{*} 100 \%$.

Elevated plus maze

The elevated plus maze test was used to assess anxiety-like behaviour and was conducted as previously described (Burokas et al. 2017). The elevated plus maze apparatus was elevated 1 meter above the ground and consisted of a grey cross-shaped maze with two open arms and two closed arms $(50 \times 5 \mathrm{~cm}$ with $15 \mathrm{~cm}$ walls in the closed arms and $1 \mathrm{~cm}$ walls in the open arms). Mice were allowed to explore the maze for $5 \mathrm{~min}$. Mice were habituated to the room 30 minutes prior to the test. Experiments were conducted in red light (5 lux). The elevated plus maze apparatus was cleaned with $70 \%$ ethanol inbetween animals. Experiments were videotaped using a ceiling camera and videos were scored blinded for time spent in the open arms, which was defined as all paws in the open arm.

\section{Tail-suspension test}

The tail-suspension test was used to assess depressive-like behaviour and was conducted as previously described (Burokas et al. 2017). Mice were hung by their tail using adhesive tape ( $2 \mathrm{~cm}$ from the tip of the tail) to a $30 \mathrm{~cm}$-elevated grid bar for 6 min. Experiments were videotaped using a numeric tripod-fixed camera and videos were scored blinded for the time mice spent immobile.

Stress-induced hyperthermia test

The stress-induced hyperthermia test was used to assess stress-responsiveness, which was conducted as previously described (Burokas et al. 2017). Body temperature was determined at baseline (T1) and 15 minutes later (T2) by gently inserting a Vaseline-covered thermometer $2.0 \mathrm{~cm}$ into the rectum. The temperature was noted to the nearest $0.1^{\circ} \mathrm{C}$ after it stabilised $(\sim 10 \mathrm{~s})$. Mice were restrained by scruffing during this procedure which was the stressor. Animals were habituated to the testing room 1 hour prior to the test. The difference between T1 and T2 reflected the stress-induced hyperthermia. 
Intestinal motility assay

Gastrointestinal motility was assessed as previously described (Golubeva et al. 2017). Briefly, mice were single-housed at $8.00 \mathrm{a} . \mathrm{m}$. with ad libitum access to food and drinking water. Three hours later, $0.2 \mathrm{~mL}$ of non-absorbable $6 \%$ carmine red in $0.5 \%$ methylcellulose dissolved in sterile phosphate-buffered saline was administered by oral gavage, after which drinking water was removed. The latency for the excretion of the first red-coloured faecal pellet was subsequently timed as a measure of gastrointestinal motility.

Assessment of faecal water content and weight

Mice were single-housed for one hour during which faecal pellets were collected ( \pm 9 per animal). Pellets were subsequently weighed, incubated at $50{ }^{\circ} \mathrm{C}$ for 24 hours and weighed again. The average weight per pellet and percentage of faecal water content was calculated. In addition, on a separate day, animals were single housed prior to the start of the active-phase for 24-hours. Faecal pellets from the entire cage were subsequently collected and animals were placed back into their original housing cages.

FITC-Dextran intestinal permeability test

Gastrointestinal permeability was assessed using the FITC-dextran intestinal permeability test, which was conducted as previously described (van de Wouw et al. 2018). Mice were fastened overnight and received an oral gavage of FITC-dextran dissolved in sterile PBS (Sigma, FD4) at 9 a.m. The administered dosage was $600 \mathrm{mg} / \mathrm{kg}$ body weight, and the approximate volume administered per mouse was $0.21 \mathrm{ml}$. Two hours after the FITC-dextran was administered, approximately $50 \mu$ of whole blood was taken by tail-tip. For this procedure, the end of the tail was held with two fingers without restraining the mouse. A 2-4 mm long diagonal incision was made at the end of the tail using a single edge razor blade, and blood was collected in an EDTA-containing capillary. Blood was then transferred to a tube, centrifuged for 15 min at $3.500 \mathrm{~g}$ at $4{ }^{\circ} \mathrm{C}$, and plasma was collected and stored at $-80^{\circ} \mathrm{C}$ for later analysis. Plasma FITC-dextran concentrations were assessed with a multi-mode plate reader (Victor 3, Perkin Elmer) with an excitation of $490 \mathrm{~nm}$ and emission of $520 \mathrm{~nm}$.

Fear conditioning

Fear conditioning was used as a assess amygdala-dependent learning memory and was conducted as previously described (Izquierdo et al. 2006). The test consisted of 3 days/phases; 1) Training, 2) Assessment of cued memory, 3) Assessment of contextual memory, each of which was carried on successive days with a 24-hour interval. In phase 1 (training), animals were recorded for 3 minutes (baseline), followed by 6 tone-conditioned stimuli (70 dB, $20 \mathrm{~s})$, followed by a foot shock $(0.6 \mathrm{~mA}, 2 \mathrm{~s})$, with a 1-minute interval. In phase 2 (Assessment of cued memory), mice were placed in a novel context (i.e. black-checkered walls with a solid Plexiglas opaque floor, under which paper was placed containing a $400 \mu$ vanilla solution ( $79.5 \%$ water/ $19.5 \%$ ethanol/1\% vanilla-extract solution), and after an initial acclimation period of 2 minutes, mice received 40 presentations of the tone-conditioned stimuli, each lasting 30 seconds with a 5 -second interval. In phase 3 (Assessment of contextual memory), mice were 
placed in the context of day 1 and recorded for 5 minutes, without the presentation of any toneconditioned stimuli. The fear conditioning apparatus was cleaned with $70 \%$ ethanol in-between animals.

Forced swim test

The forced swim test was used to assess depressive-like behaviour and was conducted as previously described (Cryan et al. 2004). Mice were individually placed in a transparent glass cylinder $(24 \times 21 \mathrm{~cm}$ diameter) containing $15-\mathrm{cm}$-depth water $\left(23-25^{\circ} \mathrm{C}\right)$ for 6 minutes. Mice were gently dried after the test and water was renewed after each animal. Experiments were videotaped using a ceiling camera and videos were scored blinded for immobility time in the last 4 min of the test.

Repeated plasma sampling for corticosterone quantification

Plasma from each animal was sampled by tail-tip five minutes before the forced swim test, and repeatedly after the test in 30-min intervals up to 120 minutes. For the tail-tip, the end of the tail was gently held with two fingers without restraining the mouse. Using a single edge razor blade, a 2-4 mm long diagonal incision was made at the end of the tail. Approximately $40 \mu \mathrm{l}$ of whole blood was taken per time point using an EDTA-containing capillary (Fisher Scientific, 749311), deposited in an Eppendorf and centrifuged for $10 \mathrm{~min}$ at $3,500 \mathrm{~g}$ at $4{ }^{\circ} \mathrm{C}$. Plasma was collected and stored at $-80^{\circ} \mathrm{C}$ for later corticosterone quantification.

Tissue collection

Collection of faecal samples throughout the study was done by single housing mice until 3 pellets were dropped between 10.00 and 12.00 a.m. The order of faecal pellet collection was counterbalanced between groups to minimise the effect of circadian rhythm. Pellets were snap-frozen on dry ice within 3 minutes after excretion and subsequently stored at $-80^{\circ} \mathrm{C}$. Faecal pellets from week 8 were used for monoamine quantification using high-performance liquid chromatography (HPLC).

Animals were sacrificed by decapitation in a random fashion regarding test groups between 9.00 a.m. and 2.00 p.m. Trunk blood was collected in EDTA-containing tubes and $100 \mu \mathrm{l}$ was put in a separate Eppendorf for flow cytometry. Both tubes were centrifuged for $10 \mathrm{~min}$ at $3,500 \mathrm{~g}$ at $4{ }^{\circ} \mathrm{C}$, after which plasma was collected and stored at $-80^{\circ} \mathrm{C}$ for later analysis. The remaining cell pellet of the Eppendorf containing $100 \mu \mathrm{l}$ blood was stored at $4{ }^{\circ} \mathrm{C}$ and subsequently used for flow cytometry. Mesenteric lymph nodes (MLNs) were dissected, cleaned from fat tissue and in stored in RPMI-1640 medium with Lglutamine and sodium bicarbonate (R8758, Sigma), supplemented with 10\% FBS (F7524I, Sigma) and 1\% Pen/strep (P4333, Sigma) at $4{ }^{\circ} \mathrm{C}$ for subsequent flow cytometry. The caecum was weighed, snap-frozen on dry ice and stored at $-80^{\circ} \mathrm{C}$. The length of the colon was measured, and the proximal and distal $2 \mathrm{~cm}$ were collected and cut in half. One side was snap-frozen on dry ice and stored at $-80^{\circ} \mathrm{C}$ and the other treated with RNAlater (Sigma, R0901). This was done by incubating the tissues for 48 hours at $4{ }^{\circ} \mathrm{C}$, after which the RNAlater was removed and tissues were stored at $-80^{\circ} \mathrm{C}$ for later gene expression analysis. Whole brains were snap-frozen in ice-cold isopentane and stored at $-80^{\circ} \mathrm{C}$. For mucus staining, a part 
$1.5 \mathrm{~cm}$ of the distal colon was collected containing a faecal pellet to ensure the integrity of the mucus layer. The tissue was subsequently incubated in Carnoy's solution ( $100 \%$ ethanol, chloroform and glacial acetic acid in a ratio of $6: 3: 1)$ for 2 hours at $4{ }^{\circ} \mathrm{C}$ and subsequently stored in $100 \%$ ethanol at $4{ }^{\circ} \mathrm{C}$ for later paraffin embedding.

Intestinal permeability by Ussing chamber

This assay was used to assess ileal and colonic permeability ex vivo and was performed as previously described with minor modifications (Golubeva et al. 2017). A piece of distal ileum (1.5 cm segment taken $2.0 \mathrm{~cm}$ proximally from the caecum) and proximal colon (1.0 cm segment) were emptied of their contents, cleaned and put in Krebs buffer (1.2 mM NaH2PO4, $117 \mathrm{mM} \mathrm{NaCl}, 4.8 \mathrm{mM} \mathrm{KCl}, 1.2 \mathrm{mM} \mathrm{MgCl}$, $25 \mathrm{mM} \mathrm{NaHCO} 3,11 \mathrm{mM} \mathrm{CaCl} 2$ and $10 \mathrm{mM}$ glucose). The samples were mounted within 5 minutes in Ussing chambers with an exposed tissue area of $0.12 \mathrm{~cm}^{2}$. No seromuscular stripping was performed. The permeability of the epithelial layer was measured via paracellular flux of $4 \mathrm{kDa}$ FITC-dextran (SigmaAldrich, FD4). FITC-dextran was added to the mucosal chamber at a final concentration of $2.5 \mathrm{mg} / \mathrm{mL}$. To assess serosal-to-mucosal FITC flux across the epithelium, $200 \mu \mathrm{L}$ was collected from the serosal chamber at baseline and after 60,90 and 120 minutes. FITC absorbance was measured at $485 \mathrm{~nm}$ excitation/535 nm emission wavelengths through fluorometric analysis using a multi-mode plate reader (Victor 3, Perkin Elmer). FITC flux was then calculated as an increment in fluorescence intensity vs baseline fluorescence in the serosal compartment and presented in $\mathrm{ng} / \mathrm{mL}$.

Flow cytometry

Flow cytometry was performed as previously described (Gururajan et al. 2019, van de Wouw et al. 2019). Blood analysed using flow cytometry was collected prior to the forced-swim test, as well as 30 and 120 minutes following it. MLNs collected when animals were sacrificed. All samples were processed on the same day for flow cytometry. Blood was resuspended in $10 \mathrm{~mL}$ home-made red blood cell lysis buffer (15.5 mM NH 4 Cl, $1.2 \mathrm{mM} \mathrm{NaHCO}_{3}, 0.01 \mathrm{mM}$ tetrasodium EDTA diluted in deionised water) for 3 minutes. Blood samples were subsequently centrifuged (1500 g, 5 minutes), split into 2 aliquots and resuspended in $45 \mu$ staining buffer (autoMACS Rinsing Solution (Miltenyi, 130-091-222) supplemented with MACS BSA stock solution (Miltenyi, 130-091-376)) for the staining procedure. MLNs were poured over a $70 \mu \mathrm{m}$ strainer and disassembled using the plunger of a $1 \mathrm{~mL}$ syringe. The strainer was subsequently washed with $10 \mathrm{~mL}$ media (RPMI-1640 medium with L-glutamine and sodium bicarbonate, supplemented with $10 \%$ FBS and $1 \%$ Pen/strep), centrifuged and $1 \times 10^{6}$ cells were resuspended in $45 \mu$ staining buffer for the staining procedure. For the staining procedure, $5 \mu \mathrm{l}$ of FcR blocking reagent (Miltenyi, 130-092-575) was added to each sample. Samples were subsequently incubated with a mix of antibodies (Blood aliquot 1; $5 \mu \mathrm{l} \mathrm{CD11b-VioBright} \mathrm{FITC} \mathrm{(Miltenyi,} \mathrm{130-109-290),} 5 \mu \mathrm{l} \mathrm{LY6C-PE} \mathrm{(Miltenyi,} \mathrm{130-102-391),} 0.3 \mu \mathrm{l}$ CX3CR1-PerCP-Cyanine5.5 (Biolegend, 149010) and $5 \mu$ I CCR2-APC (Miltenyi, 130-108-723 MLNs; $1 \mu \mathrm{l}$ CD4-FITC (ThermoFisher, 11-0042-82) and $1 \mu \mathrm{l} \mathrm{CD25-PerCP-Cyanine5.5} \mathrm{(ThermoFisher,} \mathrm{45-0251-80)} \mathrm{)} \mathrm{and}$ incubated for 30 minutes on ice. Blood samples were subsequently fixed in 4\% PFA for 30 minutes on ice, whilst and MLNs underwent intracellular staining using the eBioscience ${ }^{T M}$ Foxp3 / Transcription Factor 
Staining Buffer Set (ThermoFisher, 00-5523-00), according to the manufacturers' instructions, using antibodies for intracellular staining ( $2 \mu$ l FoxP3-APC (ThermoFisher, 17-5773-82) and $5 \mu$ l Helios-PE (ThermoFisher, 12-9883-42)). Fixed samples were resuspended in staining buffer and analysed the subsequent day on the BD FACSCalibur flow cytometry machine. Data were analysed using FlowJo (version 10). The investigated cell populations were normalised to PBMC levels.

Plasma corticosterone and cytokine assessment

Corticosterone quantification of plasma samples $(20 \mu \mathrm{l})$ obtained in the forced swim test was performed using a corticosterone ELISA (Enzo Life Sciences, ADI-901-097) according to the manufacturer's guidelines. Plasma adrenaline and noradrenaline were quantified using an ELISA (Abnova, KA1877) according to the manufacturer's instructions with one minor modification, where $15 \mu \mathrm{L}$ plasma was used instead of $300 \mu \mathrm{L}$. Absorbance was read using a Biotek Synergy $\mathrm{H} 1$ plate reader equipped with Gen5 software (Biotek, Winooski, VT, USA). Cytokine levels from plasma samples collected during euthanasia were quantified using the V-PLEX Proinflammatory Panel 1 Mouse Kit (MSD, K15048D). Cytokine quantification was done according to the manufacturer's guidelines with one modification, where $20 \mu \mathrm{l}$ plasma sample was added onto the plate and incubated overnight ( 15 hours) at $4{ }^{\circ} \mathrm{C}$, after which the rest of the protocol was carried out as suggested by the guideline. Values under the fit curve range and detection range were excluded.

Colonic mucus layer staining

Colonic samples were embedded in paraffin with a histokinette (Leica TP1020 Tissue Processor) using the following program: $100 \%$ ethanol $-90 \mathrm{~min} ; 50 \%$ ethanol/50\% histoclear $-60 \mathrm{~min} ; 2$ cycles $100 \%$ histoclear $-120 \mathrm{~min} ; 2$ cycles $100 \%$ paraffin at $60^{\circ} \mathrm{C}-120 \mathrm{~min}$. Tissues were subsequently cut in half, oriented for transversal sectioning and embedded in paraffin blocks using the Tissue-Tek ${ }^{\circledR}$ TEC ${ }^{\text {TM }} 5$ apparatus (Sakura). Samples were sectioned $(8 \mu \mathrm{m})$ using the rotary microtome Leica RM2135 and left to dry at $50^{\circ} \mathrm{C}$ for $24 \mathrm{~h}$.

Sections were stained with alcian blue and periodic acid for the mucus layer, with Nuclear fast red as a counterstain. Briefly, histolene - 10 min; 2 cycles 100\% ethanol - 5 min; 95\% ethanol - 5 min; 70\% ethanol - 5 min; tap water - 10 min; $3 \%$ acetic acid - 3 min; $1 \%$ alcian blue (Sigma Aldrich, 8GX. Acian blue was dissolved in 3\% acetic acid, stirred overnight, brought to a pH of 2.5, and filtered) $-30 \mathrm{~min} ; 3 \%$ acetic acid - $10 \mathrm{sec}$; tap water $-2 \mathrm{~min}$; distilled water - one rinse; $0.5 \%$ periodic acid (Acros Organics, A0374808) - 5 min; distilled water - one rinse; Schiff's reagent (Fisher Scientific, 1713072) - 10 min; tap water - 5 min; Nuclear fast red (Sigma Aldrich, N3020) - 5 min; tap water - 1 min; $95 \%$ ethanol - 3 min; $100 \%$ ethanol $-3 \mathrm{~min} ; 100 \%$ ethanol -3 min. Finally, sections were covered with a cover-slip using DPX mounting.

Pictures were taken using full-bright microscopy (Olympus BX51 brightfield Microscope) and analysed using. The mucus thickness $(\mu \mathrm{m})$ was subsequently measured using ImageJ2 software. As mucus thickness measurements of the same animal were quite variable between different pictures, we chose to 
take 81 measurements per animal. Specifically, 3 pictures were made of each of 9 different sections, after which 3 measurements were taken of each picture. These 81 measurements were non-normally distributed, so the median was taken of all measurements, which represented the colonic mucus thickness of that animal.

High-performance liquid chromatography

5-hydroxytryptamine (5-HT) and 5-hydroxyindoleacetic acid (5-HIAA) concentrations were determined using HPLC based on methodology previously described (Clarke et al. 2013). Briefly, mobile phase consisted of HPLC-grade $0.1 \mathrm{M}$ citric acid, $0.1 \mathrm{M}$ sodium dihydrogen phosphate monohydrate, $0.01 \mathrm{mM}$ EDTA disodium salt (Alkem/Reagecon), $5.6 \mathrm{mM}$ octane-1-sulphonic acid (Sigma Aldrich), and 9\% (v/v) methanol (Alkem/Reagecon). The pH of the mobile phase was adjusted to 2.8 using $4 \mathrm{~N}$ sodium hydroxide (Alkem/Reagecon). Homogenization buffer consisted of mobile phase with the addition of $20 \mathrm{ng} / 20 \mu \mathrm{l}$ of the internal standard, N-methyl 5-HT (Sigma Aldrich). Briefly, tissue samples were sonicated (Sonopuls HD 2070) for 4 seconds in $500 \mu \mathrm{l}$ cold homogenization buffer during which they were kept chilled. Tissue homogenates were then centrifuged at $14,000 \mathrm{~g}$ for $20 \mathrm{~min}$ at $4^{\circ} \mathrm{C}$. The supernatant was collected and the pellet was discarded. The supernatant was then briefly vortexed and $30 \mu \mathrm{l}$ of supernatant was spiked into $270 \mu \mathrm{l}$ of mobile phase. $20 \mu \mathrm{l}$ of the 1:10 dilution was injected into the HPLC system (Shimadzu, Japan) which was comprised of a SCL 10-Avp system controller, LC-10AS pump, SIL-10A autoinjector, CTO-10A oven, LECD 6A electrochemical detector, and Class VP-5 software. The chromatographic conditions were flow rate of $0.9 \mathrm{~mL} / \mathrm{min}$ using a Kinetex $2.6 \mathrm{u}$ C18 100A x $4.6 \mathrm{~mm}$ column (Phenomenex), oven temperature of $30^{\circ} \mathrm{C}$, and detector settings of $+0.8 \mathrm{~V}$. 5-HT and 5-HIAA external standards (Sigma Aldrich, $\mathrm{H} 7752$ and $\mathrm{H} 8876$, respectively) were injected at regular intervals during sample analyses. Monoamines in unknown samples were determined by their retention times compared to external standards. Peak heights of the analyte: internal standard ratio were measured and compared with external standards, results were expressed as $\mu \mathrm{g}$ of neurotransmitter per gram of tissue.

Statistical analysis

All behavioural and physiological data were assessed for normality using the Shapiro-Wilk test and Levene's test for equality of variances. The effect of kefir was determined by an unpaired Student's t-test when data were normally distributed and Mann-Whitney $U$ test when data were non-normally distributed. Body weight and fear conditioning data were assessed using repeated measures ANOVA. Statistical significance for social preference and recognition in the 3-chamber sociability test was assessed using Wilcoxon signed ranks test. Parametric data is depicted as bar graphs with points as individual data points and expressed as mean \pm SEM. Non-parametric data is depicted as a box with whiskers plot. Statistical analysis was performed using SPSS software version 24 (IBM Corp). A p-value $<0.05$ was deemed significant.

\section{Results}


Kefir is well-tolerated in BTBR mice

No differences were found in body weight, locomotor activity or the weight of various adipose deposits between test and control mice throughout the study, indicating that kefir was well-tolerated in BTBR mice (Fig. 2).

Kefir reduces repetitive behaviour in the marble burying test

Previous work from our lab has shown that BTBR mice have an enhanced engagement in repetitive behaviours in the marble burying test compared to C57BL/6 mice (Golubeva et al. 2017). Mice receiving kefir showed a trend towards decreased marbles buried $(t(17)=2.104, p=0.051)$ (Fig. 3A). This was confirmed by measuring the time mice spent engaging in burying behaviour throughout this test $(U=18$, $p=0.033)$ (Fig. 3B).

Kefir does not affect other measures of anxiety- and depressive-like behaviour

No differences were found in any of the other tests addressing anxiety-like behaviour, which included the assessment of self-grooming behaviour (Fig. 4A), the open field test (Fig. 4B), the elevated plus maze (Fig. 4C) and the stress-induced hyperthermia test (Fig. 4D). In addition, no changes were observed in any of the tests assessing depressive-like behaviour, like the tail suspension test (Fig. 4E) and forced swim test (Fig. 4F).

Mice receiving kefir show significant social recognition

Previous work from our lab has shown that BTBR mice show decreased social preference and recognition compared to C57BL/6 mice (Golubeva et al. 2017). Both mice receiving milk and kefir showed social preference (milk: $(t(10)=-3.995, p=0.003)$; kefır: $(Z=-1.956, p=0.050)$ (Fig. 5A). No differences in the social preference ratio were observed (Fig. 5B). However, mice receiving milk only showed a trend towards social recognition $(Z=-1.778, p=0.075)$, while mice receiving kefir showed significance social recognition $(Z=-2.073, p=0.038)$ (Fig. $5 \mathrm{C}$ ). Nonetheless, no differences in the social recognition ratio were observed (Fig. 5D).

Kefir does not affect fear-dependent learning and memory

Kefir administration does not influence fear-dependent learning, nor cued and contextual memory in the fear conditioning test (Fig. 6A-D).

Kefir ameliorates stress-induced monocyte trafficking

Previous work has shown that BTBR mice have an increased HPA-axis reactivity in response to acute stress as measured by increased levels of plasma corticosterone levels in response to an acute stressor (Golubeva et al. 2017). This stress-induced increase in corticosterone, as well as catecholamines, is associated with a peripheral immune cell distribution, indicating immune cell trafficking (Dhabhar et al. 2012, van de Wouw et al. 2019). We therefore first investigated the corticosterone response to an acute 
stressor (i.e. forced swim test), where we observed that kefir prolonged stress-induced corticosterone increases at 60 minutes post-stress only $(U=13, p=0.009)$ (Fig. 7A). No differences were observed in levels of the catecholamine adrenalin and noradrenalin (Fig. 7B, C). We subsequently investigated changes in blood monocyte levels in response to stress. In line with previous reports (van de Wouw et al. 2019), acute stress decreased LY6C ${ }^{\text {hi }}$ monocyte (CD11b+, LY6C hi levels) $(F(2,59)=72.243, p<0.001)$ (Fig. 7E). Interestingly, there was a trend towards amelioration of this stress-induced effect in mice receiving kefir as detected by absolute levels of $L Y 6 C^{\text {hi }}$ monocytes $(t(18)=-1.819, p=0.086)$ (Fig. 7E), and relative decrease $(t(18)=2.284, p=0.035)(F i g .7 F)$. Considering the pivotal role of the CCR2 receptor in LY6C ${ }^{\text {hi }}$ monocyte trafficking (Prinz et al. 2010), we hypothesised that changes in CCR2 receptor expression could be underlying these acute stress-induced differences in LY6C ${ }^{\text {hi }}$ monocytes. Indeed, acute stress increased CCR2 receptor expression $(F(2,59)=40.874, p<0.001)$ (Fig. 7G), and a trend towards decreased stress-induced increase in CCR2 receptor expression was observed in mice receiving kefir $(\mathrm{t}(18)$ $=-1.747, p=0.098)($ Fig. 7G).

Kefir increases T regulatory cells in mesenteric lymph nodes

Previous reports show that individuals with ASD, as well as BTBR mice have decreased CD4+, FoxP3 + cells, indicating decreased Treg cell levels (Ahmad et al. 2017, Bakheet et al. 2017). We found that kefir did not affect T helper cells (CD4+) levels in mesenteric lymph nodes (MLNs) (Fig. 8B), even though kefir did increase Treg cell $(C D 4+, C D 25+$, FoxP3 + ) levels $(t(18)=-3.003, p=0.008)$ (Fig. 8C). This increase in Treg cells could not be attributed by Treg cells specifically originating from the thymus (Helios + ) or periphery (Helios-) (Fig. 8D). Surprisingly, even though a trend in decreased T helper cells (CD4+) was observed in the circulation ( $t(18)=1.835, p=0.083$ ) (Fig. 8E), no corresponding changes were observed in the peripheral circulation (Fig. 8F). Furthermore, no differences were observed in plasma IL-10 levels, one of the primary cytokines secreted by Treg cells (Fig. 8G) (Sabat et al. 2010).

Kefir does not affect intestinal permeability

Considering previous work has shown that BTBR mice have decreased MUC2 mRNA expression in the colon, which is the primary constituent of the mucus layer, we wondered if kefir could influence the colonic mucus layer (Golubeva et al. 2017). However, kefir administration did not affect colonic mucus thickness (Fig. 9B). Similarly, it was previously reported that BTBR mice have increased epithelial permeability (Golubeva et al. 2017), which also remained unaffected by kefir treatment as measured in vivo (Fig. 9C), and ex vivo (Fig. 9D, E).

Kefir does not change gut serotonin levels and gastrointestinal motility

BTBR have previously been shown to have decreased 5-HT levels in the colon and ileum, as well as decreased intestinal motility compared to C57BL/6 mice (Golubeva et al. 2017). We hypothesised that kefir administration might ameliorate these deficits, but we did not observe any kefir-induced difference in ileal 5HIAA, 5-HT levels, as well as in the 5HIAA/5-HT ratio (Fig. 10A-C). In addition, no differences were present in colonic 5-HT levels and the 5HIAA/5-HT ratio (Fig. 10E, F), even though a trend was observed 
towards decreased 5HIAA levels $(U=21, p=0.062)$ (Fig. 10D). Similarly, we did not observe any differences in gastrointestinal motility as determined by carmine red administration (Fig. 10G), average faecal pellet weight (Fig. 10H), faecal water content (Fig. 10I) and colon length (Fig. 10J). Interestingly, kefir UK4 did increase cecum weights $(U=17, p=0.017)$ (Fig. 10K). Notably, previous work from our lab has shown that BTBR mice have no altered cecum weight compared to C57BL/6 mice (data not published).

\section{Discussion}

In the present study, we demonstrate that kefir supplementation was well-tolerated and improved the repetitive behaviour of BTBR mice, a mouse model of ASD (Golubeva et al. 2017). In addition, kefir prolonged stress-induced corticosterone responses and ameliorated the immune response to an acute stressor. Finally, kefir increased the level of anti-inflammatory Treg cells in MLNs and increased the caecum size of BTBR mice.

Many of the behavioural and physiological findings are consistent with our previous data in normal C57BL/ 6 mice (Van de Wouw et al. Unpublished). For instance, these previous studies showed that kefir UK4 decreased repetitive behaviour and increased Treg cells in MLNs, whereas other measures of anxiety and depressive-like behaviour, gastrointestinal motility and gut serotonin levels remained unaffected in control mice. Some divergence did emerge between the effects of kefir UK4 in BTBR mouse versus that shown in C57BL/ 6 mice, with kefir UK4 failing to increase fear-dependent contextual learning or peripheral Treg cell levels in the former strain. These latter differences might be explained by the way kefir affects these different mouse strains as, for instance, fear-dependent learning is decreased in BTBR mice (Stapley et al. 2013). Overall, this indicates that the physiological and behavioural effects of the fermented milk drink kefir are reproducible.

We show that specific behavioural deficits in BTBR mice were alleviated, such as an increased engagement in repetitive behaviour (Golubeva et al. 2017). Furthermore, mice receiving kefir showed social recognition, which was absent in mice receiving milk. Nonetheless, no significant difference was found in the social recognition index between the two groups. Previous studies have also indicated that the gut microbiota provides a potential therapeutic target for ASD (Hsiao et al. 2013, Kumar et al. 2016). For instance, repeated intraperitoneal administration of the gut microbial-derived metabolite butyrate has also been shown to attenuates social deficits and repetitive behaviour in BTBR mice (Kratsman et al. 2016). These observed changes were associated with increased GABAergic signalling in the prefrontal cortex as indicated by increased GABA receptor subunit gamma- 1 gene expression. In addition, subsequent administration of a reverse agonist of the $G_{A B A}$ receptor reversed the effects of butyrate on social deficits, indicating that butyrate ameliorates social deficits in BTBR mice by enhancing GABAergic signalling (Kratsman et al. 2016). Similarly, the consumption of a fermented milk product containing probiotic bacteria changed the activity of the prefrontal cortex in healthy women (Tillisch et al. 2013). We have previously shown that this kefir increases the capacity of the microbiota to produce GABA (Van de Wouw et al. Unpublished), indicating that kefir might have increased GABA signalling in this study. 
The BTBR mouse model also displays a persistent immune dysregulation, similar to what has been reported in individuals with ASD (Careaga et al. 2015). For instance, elevated T cell activation in the circulation (Ashwood et al. 2011), decreased anti-inflammatory Treg cells (Ahmad et al. 2017), and increased IFNY expression and Th1/2 ratio in the cortex have been reported (Li et al. 2009). Similarly, BTBR mice show increased T helper cell activation, decreased levels of anti-inflammatory Treg cells and changes in transcription factor expression associated with T helper cell subsets in the CNS (Zhang et al. 2013, Bakheet et al. 2017). Our data demonstrated that kefir administration increases the prevalence of Treg cells in MLNs, even though Treg cell and IL-10 levels remained unaffected in the peripheral circulation.

Our data also showed that kefir prolonged stress-induced increases in plasma corticosterone 60 minutes post-stress. Even though acute stress, as well as increases in corticosterone, have previously been associated with innate immune cell trafficking and activation (Dhabhar et al. 2012, Bobel et al. 2018, Boehme et al. 2019, van de Wouw et al. 2019), kefir ameliorated acute stress-induced LY6C ${ }^{\text {hi }}$ monocyte trafficking, which was associated with a trend towards reduced stress-induced expression of the trafficking receptor CCR2 (Prinz et al. 2010). It is therefore interesting to note that stress-induced changes in glucocorticoids have been implicated in both the activation of the immune system and suppression of on-going stress-responses (Sapolsky et al. 2000, van de Wouw et al. 2019). This might postulate the hypothesis that the initial stress-induced increase in corticosterone facilitates immune cells trafficking, after which corticosterone could contribute to the recovery of stress-induced immune cell trafficking. Nonetheless, the finding that kefir ameliorated stress-induced decreases in LY $6 \mathrm{C}^{\text {hi }}$ monocyte and CCR2 receptor expression may indicate decreased LY6C ${ }^{\text {hi }}$ monocyte trafficking into the CNS (Prinz et al. 2010). Interestingly, ASD is associated with elevated levels of circulating cytokines associated with the innate immune system, such as IL-1 $\beta$, IL-6, IL-8 and IL-12 (Ashwood et al. 2011). In addition, increased levels of IL-1 $\beta$, IL-6, IL-8 and TNFa have been reported in the cortex of individuals with ASD (Li et al. 2009), and increased levels of CCL2, IL6, TGF- $\beta 1$ and IGFBP-1 have been demonstrated in the cerebellum, middle frontal gyrus and anterior cingulate gyrus (Vargas et al. 2005). In addition, microglia activation and increased microglia density have been reported in the dorsolateral prefrontal cortex of ASD individuals (Morgan et al. 2010). Similarly, macrophages derived from BTBR mice secrete more inflammatory cytokines, which correlates with their ASD-associated behavioural phenotype (Onore et al. 2013). Overall, these data indicate that kefir can reduce peripheral innate immune activation, which might have relevance to neuroimmune activation (Reader et al. 2015, Kim et al. 2018).

In line with previous work (Van de Wouw et al. Unpublished), kefir did not impact gut 5-HT levels and gastrointestinal motility, even though kefir did increase cecum weights. Interestingly, germ-free mice, as well as mice receiving the prebiotic GOS/inulin or antibiotics have been shown to have increased caecum sizes (Barrat et al. 2008, Grover et al. 2014, Kang et al. 2017), indicating that an altered cecum weight is neither good nor bad per se. Finally. No differences in ileal or colonic permeability were observed. In line with these findings is an absence of change in colonic mucosal layer thickness, which represents an 
additional barrier against the infiltration of gut microbes and their products into the host circulation (Johansson et al. 2011).

\section{Limitations}

It is important to note that ASD is a neurodevelopmental disorder (Lyall et al. 2017) and that the supplementation of kefir in the present study started in adulthood. As such, starting kefir administration at an earlier stage of life could potentially lead to an even greater amelioration of some of the other physiological or behavioural deficits present in BTBR mice, which remained unaffected in this study. Furthermore, different kefirs have been demonstrated to impact the gut microbiome, host immunity and behaviour in distinct ways (Van de Wouw et al. Unpublished). As such, the observed effects of the kefir strain in this study might not translate to other kefir strains.

\section{Conclusion}

These data demonstrate that the traditionally fermented milk drink kefir reduces specific behavioural impairments, as well as markers of systemic inflammation, in a mouse model of ASD. These results reinforce the notion of kefir as a potential intervention to positively modulate the microbiota-gut-brain axis and show that kefir supplementation might prove a viable strategy in improving specific symptoms in ASD.

\section{Abbreviations}

ASD

autism spectrum disorder

Treg

$T$ regulatory cell

MLN

Mesenteric lymph node

pTreg

Peripheral-derived T regulatory cells

5-HT

Serotonin

5HIAA

5-hydroxyindoleacetic acid

\section{Declarations}

\section{Ethical approval and consent to participate}

Not applicable 


\section{Consent for publication}

Not applicable

\section{Availability of data and material}

The datasets used and/or analysed during the current study are available from the corresponding author on reasonable request

\section{Funding Sources}

The APC Microbiome Ireland is a research institute funded by Science Foundation Ireland (SFI) through the Irish Government's National Development Plan. J.F.C, T.G.D and P.D.C. are supported by SFI (Grant Nos. SFI/12/RC/2273). MB is supported by an educational grant from Science Foundation Ireland (SFI), Ireland (15/JP-HDHL/3270; JPI-HDHL-NutriCog project 'AMBROSIAC').

\section{Competing Interests}

J.F.C and T.G.D have research support from Mead Johnson, Cremo, 4D Pharma, Dupont, and Nutricia. P.D.C has research support from PepsiCo and Danone. J.F.C, T.G.D and P.D.C. have spoken at meetings sponsored by food and pharmaceutical companies. All other authors report no potential conflicts of interest.

\section{Author Contributions}

M.vd.W. performed the in vivo study, behavioural analysis and flow cytometry. G.M.D.V performed the mucus staining. M.L performed the HPLC analysis. M.B. assisted with flow cytometry. A.M.W., F.C., G.C., T.G.D., P.D.C, and J.F.C contributed to the experimental design and drafting and critical revision of the manuscript.

\section{Acknowledgements}

Flow cytometry analysis was performed at the APC Microbiome Ireland Flow Cytometry Platform located at University College Cork. The authors are also grateful for the technical assistance of P. Fitzgerald and C. Manly, and the assistance with data analysis and study design by Drs G. Moloney, A. Golubeva and K. O'Riordan.

\section{References}

1. Ahmad, S. F., K. M. A. Zoheir, M. A. Ansari, A. Nadeem, S. A. Bakheet, L. Y. Al-Ayadhi, M. Z. Alzahrani, O. A. Al-Shabanah, M. M. Al-Harbi and S. M. Attia. (2017). Dysregulation of Th1, Th2, Th17, and T regulatory cell-related transcription factor signaling in children with autism. Mol Neurobiol, 54(6), 4390-4400. doi:10.1007/s12035-016-9977-0 
2. Ashwood, P., B. A. Corbett, A. Kantor, H. Schulman, J. Van de Water and D. G. Amaral. (2011). In search of cellular immunophenotypes in the blood of children with autism. PLoS One, 6(5), e19299. doi:10.1371/journal.pone.0019299

3. Ashwood, P., P. Krakowiak, I. Hertz-Picciotto, R. Hansen, I. Pessah and J. Van de Water. (2011). Elevated plasma cytokines in autism spectrum disorders provide evidence of immune dysfunction and are associated with impaired behavioral outcome. Brain Behav Immun, 25(1), 40-45. doi:10.1016/j.bbi.2010.08.003

4. Aslam, H., J. Green, F. N. Jacka, F. Collier, M. Berk, J. Pasco and S. L. Dawson. (2018). Fermented foods, the gut and mental health: a mechanistic overview with implications for depression and anxiety. Nutr Neurosci, 1-13. doi:10.1080/1028415X.2018.1544332

5. Association, A. P. (2013). Diagnostic and Statistical Manual of Mental Disorders (DSM-5®).

6. Bakheet, S. A., M. Z. Alzahrani, M. A. Ansari, A. Nadeem, K. M. A. Zoheir, S. M. Attia, L. Y. Al-Ayadhi and S. F. Ahmad. (2017). Resveratrol Ameliorates Dysregulation of Th1, Th2, Th17, and T Regulatory Cell-Related Transcription Factor Signaling in a BTBR T + tf/J Mouse Model of Autism. Mol Neurobiol, 54(7), 5201-5212. doi:10.1007/s12035-016-0066-1

7. Barrat, E., C. Michel, G. Poupeau, A. David-Sochard, M. Rival, A. Pagniez, M. Champ and D. Darmaun. (2008). Supplementation with galactooligosaccharides and inulin increases bacterial translocation in artificially reared newborn rats. Pediatr Res, 64(1), 34-39. doi:10.1203/PDR.0b013e3181732381

8. Bobel, T. S., S. B. Hackl, D. Langgartner, M. N. Jarczok, N. Rohleder, G. A. Rook, C. A. Lowry, H. Gundel, C. Waller and S. O. Reber. (2018). Less immune activation following social stress in rural vs. urban participants raised with regular or no animal contact, respectively. Proc Natl Acad Sci U S A, 115(20), 5259-5264. doi:10.1073/pnas. 1719866115

9. Boehme, M., M. van de Wouw, T. F. S. Bastiaanssen, L. Olavarria-Ramirez, K. Lyons, F. Fouhy, A. V. Golubeva, G. M. Moloney, C. Minuto, K. V. Sandhu, K. A. Scott, G. Clarke, C. Stanton, T. G. Dinan, H. Schellekens and J. F. Cryan. (2019). Mid-life microbiota crises: middle age is associated with pervasive neuroimmune alterations that are reversed by targeting the gut microbiome. Mol Psychiatry. doi:10.1038/s41380-019-0425-1

10. Bourrie, B. C., B. P. Willing and P. D. Cotter. (2016). The Microbiota and Health Promoting Characteristics of the Fermented Beverage Kefir. Front Microbiol, 7, 647. doi:10.3389/fmicb.2016.00647

11. Burokas, A., S. Arboleya, R. D. Moloney, V. L. Peterson, K. Murphy, G. Clarke, C. Stanton, T. G. Dinan and J. F. Cryan. (2017). Targeting the Microbiota-Gut-Brain Axis: Prebiotics Have Anxiolytic and Antidepressant-like Effects and Reverse the Impact of Chronic Stress in Mice. Biol Psychiatry, 82(7), 472-487. doi:10.1016/j.biopsych.2016.12.031

12. Careaga, M., J. Schwartzer and P. Ashwood. (2015). Inflammatory profiles in the BTBR mouse: how relevant are they to autism spectrum disorders? Brain Behav Immun, 43, 11-16. doi:10.1016/j.bbi.2014.06.006 
13. Clarke, G., S. Grenham, P. Scully, P. Fitzgerald, R. D. Moloney, F. Shanahan, T. G. Dinan and J. F. Cryan. (2013). The microbiome-gut-brain axis during early life regulates the hippocampal serotonergic system in a sex-dependent manner. Mol Psychiatry, 18(6), 666-673. doi:10.1038/mp.2012.77

14. Collins, S. M., M. Surette and P. Bercik. (2012). The interplay between the intestinal microbiota and the brain. Nat Rev Microbiol, 10(11), 735-742. doi:10.1038/nrmicro2876

15. Cryan, J. F. and T. G. Dinan. (2012). Mind-altering microorganisms: the impact of the gut microbiota on brain and behaviour. Nat Rev Neurosci, 13(10), 701-712. doi:10.1038/nrn3346

16. Cryan, J. F. and C. Mombereau. (2004). In search of a depressed mouse: utility of models for studying depression-related behavior in genetically modified mice. Mol Psychiatry, 9(4), 326-357. doi:10.1038/sj.mp.4001457

17. Cryan, J. F., K. J. O'Riordan, C. S. M. Cowan, K. V. Sandhu, T. F. S. Bastiaanssen, M. Boehme, M. G. Codagnone, S. Cussotto, C. Fulling, A. V. Golubeva, K. E. Guzzetta, M. Jaggar, C. M. Long-Smith, J. M. Lyte, J. A. Martin, A. Molinero-Perez, G. Moloney, E. Morelli, E. Morillas, R. O'Connor, J. S. Cruz-Pereira, V. L. Peterson, K. Rea, N. L. Ritz, E. Sherwin, S. Spichak, E. M. Teichman, M. van de Wouw, A. P. Ventura-Silva, S. E. Wallace-Fitzsimons, N. Hyland, G. Clarke and T. G. Dinan. (2019). The MicrobiotaGut-Brain Axis. Physiol Rev, 99(4), 1877-2013. doi:10.1152/physrev.00018.2018

18. D'Eufemia, P., M. Celli, R. Finocchiaro, L. Pacifico, L. Viozzi, M. Zaccagnini, E. Cardi and O. Giardini. (1996). Abnormal intestinal permeability in children with autism. Acta Paediatr, 85(9), 1076-1079.

19. De Angelis, M., M. Piccolo, L. Vannini, S. Siragusa, A. De Giacomo, D. I. Serrazzanetti, F. Cristofori, M. E. Guerzoni, M. Gobbetti and R. Francavilla. (2013). Fecal microbiota and metabolome of children with autism and pervasive developmental disorder not otherwise specified. PLoS One, 8(10), e76993. doi:10.1371/journal.pone.0076993

20. Desbonnet, L., G. Clarke, F. Shanahan, T. G. Dinan and J. F. Cryan. (2014). Microbiota is essential for social development in the mouse. Mol Psychiatry, 19(2), 146-148. doi:10.1038/mp.2013.65

21. Dhabhar, F. S., W. B. Malarkey, E. Neri and B. S. McEwen. (2012). Stress-induced redistribution of immune cells--from barracks to boulevards to battlefields: a tale of three hormones-Curt Richter Award winner. Psychoneuroendocrinology, 37(9), 1345-1368. doi:10.1016/j.psyneuen.2012.05.008

22. Dobson, A., O. O'Sullivan, P. D. Cotter, P. Ross and C. Hill. (2011). High-throughput sequence-based analysis of the bacterial composition of kefir and an associated kefir grain. FEMS Microbiol Lett, 320(1), 56-62. doi:10.1111/j.1574-6968.2011.02290.x

23. Foster, J. A., L. Rinaman and J. F. Cryan. (2017). Stress \& the gut-brain axis: Regulation by the microbiome. Neurobiol Stress, 7, 124-136. doi:10.1016/j.ynstr.2017.03.001

24. Golubeva, A. V., S. A. Joyce, G. Moloney, A. Burokas, E. Sherwin, S. Arboleya, I. Flynn, D. Khochanskiy, A. Moya-Perez, V. Peterson, K. Rea, K. Murphy, O. Makarova, S. Buravkov, N. P. Hyland, C. Stanton, G. Clarke, C. G. M. Gahan, T. G. Dinan and J. F. Cryan. (2017). Microbiota-related Changes in Bile Acid \& Tryptophan Metabolism are Associated with Gastrointestinal Dysfunction in a Mouse Model of Autism. EBioMedicine, 24, 166-178. doi:10.1016/j.ebiom.2017.09.020 
25. Grover, M. and P. C. Kashyap. (2014). Germ-free mice as a model to study effect of gut microbiota on host physiology. Neurogastroenterol Motil, 26(6), 745-748. doi:10.1111/nmo.12366

26. Gururajan, A., M. van de Wouw, M. Boehme, T. Becker, R. O'Connor, T. F. S. Bastiaanssen, G. M. Moloney, J. M. Lyte, A. Paula Ventura Silva, B. Merckx, T. G. Dinan and J. F. Cryan. (2019). Resilience to Chronic Stress Is Associated with Specific Neurobiological, Neuroendocrine and Immune Responses. Brain Behav Immun. doi:10.1016/j.bbi.2019.05.004

27. Hsiao, E. Y., S. W. McBride, S. Hsien, G. Sharon, E. R. Hyde, T. McCue, J. A. Codelli, J. Chow, S. E. Reisman, J. F. Petrosino, P. H. Patterson and S. K. Mazmanian. (2013). Microbiota modulate behavioral and physiological abnormalities associated with neurodevelopmental disorders. Cell, 155(7), 1451-1463. doi:10.1016/j.cell.2013.11.024

28. Izquierdo, A., C. L. Wellman and A. Holmes. (2006). Brief uncontrollable stress causes dendritic retraction in infralimbic cortex and resistance to fear extinction in mice. $J$ Neurosci, 26(21), 57335738. doi:10.1523/JNEUROSCI.0474-06.2006

29. Johansson, M. E., D. Ambort, T. Pelaseyed, A. Schutte, J. K. Gustafsson, A. Ermund, D. B. Subramani, J. M. Holmen-Larsson, K. A. Thomsson, J. H. Bergstrom, S. van der Post, A. M. Rodriguez-Pineiro, H. Sjovall, M. Backstrom and G. C. Hansson. (2011). Composition and functional role of the mucus layers in the intestine. Cell Mol Life Sci, 68(22), 3635-3641. doi:10.1007/s00018-011-0822-3

30. Kang, D. W., J. B. Adams, A. C. Gregory, T. Borody, L. Chittick, A. Fasano, A. Khoruts, E. Geis, J. Maldonado, S. McDonough-Means, E. L. Pollard, S. Roux, M. J. Sadowsky, K. S. Lipson, M. B. Sullivan, J. G. Caporaso and R. Krajmalnik-Brown. (2017). Microbiota Transfer Therapy alters gut ecosystem and improves gastrointestinal and autism symptoms: an open-label study. Microbiome, 5(1), 10. doi:10.1186/s40168-016-0225-7

31. Kang, D. W., J. G. Park, Z. E. Ilhan, G. Wallstrom, J. Labaer, J. B. Adams and R. Krajmalnik-Brown. (2013). Reduced incidence of Prevotella and other fermenters in intestinal microflora of autistic children. PLoS One, 8(7), e68322. doi:10.1371/journal.pone.0068322

32. Kang, M., R. A. Mischel, S. Bhave, E. Komla, A. Cho, C. Huang, W. L. Dewey and H. I. Akbarali. (2017). The effect of gut microbiome on tolerance to morphine mediated antinociception in mice. Sci Rep, 7, 42658. doi:10.1038/srep42658

33. Kim, J. W., J. Y. Hong and S. M. Bae. (2018). Microglia and Autism Spectrum Disorder: Overview of Current Evidence and Novel Immunomodulatory Treatment Options. Clin Psychopharmacol Neurosci, 16(3), 246-252. doi:10.9758/cpn.2018.16.3.246

34. Kratsman, N., D. Getselter and E. Elliott. (2016). Sodium butyrate attenuates social behavior deficits and modifies the transcription of inhibitory/excitatory genes in the frontal cortex of an autism model. Neuropharmacology, 102, 136-145. doi:10.1016/j.neuropharm.2015.11.003

35. Kumar, H. and B. Sharma. (2016). Minocycline ameliorates prenatal valproic acid induced autistic behaviour, biochemistry and blood brain barrier impairments in rats. Brain Res, 1630, 83-97. doi:10.1016/j.brainres.2015.10.052 
36. Langgartner, D., C. A. Lowry and S. O. Reber. (2018). Old Friends, immunoregulation, and stress resilience. Pflugers Arch. doi:10.1007/s00424-018-2228-7

37. Li, X., A. Chauhan, A. M. Sheikh, S. Patil, V. Chauhan, X. M. Li, L. Ji, T. Brown and M. Malik. (2009). Elevated immune response in the brain of autistic patients. $J$ Neuroimmunol, 207(1-2), 111-116. doi:10.1016/j.jneuroim.2008.12.002

38. Lowry, C. A., D. G. Smith, P. H. Siebler, D. Schmidt, C. E. Stamper, J. E. Hassell, Jr., P. S. Yamashita, J. H. Fox, S. O. Reber, L. A. Brenner, A. J. Hoisington, T. T. Postolache, K. A. Kinney, D. Marciani, M. Hernandez, S. M. Hemmings, S. Malan-Muller, K. P. Wright, R. Knight, C. L. Raison and G. A. Rook. (2016). The Microbiota, Immunoregulation, and Mental Health: Implications for Public Health. Curr Environ Health Rep, 3(3), 270-286. doi:10.1007/s40572-016-0100-5

39. Luna, R. A., N. Oezguen, M. Balderas, A. Venkatachalam, J. K. Runge, J. Versalovic, J. VeenstraVanderWeele, G. M. Anderson, T. Savidge and K. C. Williams. (2017). Distinct MicrobiomeNeuroimmune Signatures Correlate With Functional Abdominal Pain in Children With Autism Spectrum Disorder. Cell Mol Gastroenterol Hepatol, 3(2), 218-230. doi:10.1016/j.jcmgh.2016.11.008

40. Lyall, K., L. Croen, J. Daniels, M. D. Fallin, C. Ladd-Acosta, B. K. Lee, B. Y. Park, N. W. Snyder, D. Schendel, H. Volk, G. C. Windham and C. Newschaffer. (2017). The Changing Epidemiology of Autism Spectrum Disorders. Annu Rev Public Health, 38, 81-102. doi:10.1146/annurev-publhealth031816-044318

41. Mayer, E. A., R. Knight, S. K. Mazmanian, J. F. Cryan and K. Tillisch. (2014). Gut Microbes and the Brain: Paradigm Shift in Neuroscience. The Journal of Neuroscience, 34(46), 15490.

42. McElhanon, B. O., C. McCracken, S. Karpen and W. G. Sharp. (2014). Gastrointestinal symptoms in autism spectrum disorder: a meta-analysis. Pediatrics, 133(5), 872-883. doi:10.1542/peds.2013-3995

43. Morgan, J. T., G. Chana, C. A. Pardo, C. Achim, K. Semendeferi, J. Buckwalter, E. Courchesne and I. P. Everall. (2010). Microglial activation and increased microglial density observed in the dorsolateral prefrontal cortex in autism. Biol Psychiatry, 68(4), 368-376. doi:10.1016/j.biopsych.2010.05.024

44. Moy, S. S., J. J. Nadler, N. B. Young, A. Perez, L. P. Holloway, R. P. Barbaro, J. R. Barbaro, L. M. Wilson, D. W. Threadgill, J. M. Lauder, T. R. Magnuson and J. N. Crawley. (2007). Mouse behavioral tasks relevant to autism: phenotypes of 10 inbred strains. Behav Brain Res, 176(1), 4-20. doi:10.1016/j.bbr.2006.07.030

45. Murray, E., R. Sharma, K. B. Smith, K. D. Mar, R. Barve, M. Lukasik, A. F. Pirwani, E. Malette-Guyon, S. Lamba, B. J. Thomas, H. Sadeghi-Emamchaie, J. Liang, J. F. Mallet, C. Matar and N. Ismail. (2019). Probiotic consumption during puberty mitigates LPS-induced immune responses and protects against stress-induced depression- and anxiety-like behaviors in adulthood in a sex-specific manner. Brain Behav Immun, 81, 198-212. doi:10.1016/j.bbi.2019.06.016

46. Onore, C. E., M. Careaga, B. A. Babineau, J. J. Schwartzer, R. F. Berman and P. Ashwood. (2013). Inflammatory macrophage phenotype in BTBR T+tf/J mice. Front Neurosci, 7, 158. doi:10.3389/fnins.2013.00158 
47. Prinz, M. and J. Priller. (2010). Tickets to the brain: role of CCR2 and CX3CR1 in myeloid cell entry in the CNS. J Neuroimmunol, 224(1-2), 80-84. doi:10.1016/j.jneuroim.2010.05.015

48. Reader, B. F., B. L. Jarrett, D. B. McKim, E. S. Wohleb, J. P. Godbout and J. F. Sheridan. (2015). Peripheral and central effects of repeated social defeat stress: monocyte trafficking, microglial activation, and anxiety. Neuroscience, 289, 429-442. doi:10.1016/j.neuroscience.2015.01.001

49. Rhee, S. H., C. Pothoulakis and E. A. Mayer. (2009). Principles and clinical implications of the braingut-enteric microbiota axis. Nat Rev Gastroenterol Hepatol, 6(5), 306-314. doi:10.1038/nrgastro.2009.35

50. Sabat, R., G. Grutz, K. Warszawska, S. Kirsch, E. Witte, K. Wolk and J. Geginat. (2010). Biology of interleukin-10. Cytokine Growth Factor Rev, 21(5), 331-344. doi:10.1016/j.cytogfr.2010.09.002

51. Sapolsky, R. M., L. M. Romero and A. U. Munck. (2000). How do glucocorticoids influence stress responses? Integrating permissive, suppressive, stimulatory, and preparative actions. Endocr Rev, 21(1), 55-89. doi:10.1210/edrv.21.1.0389

52. Sherwin, E., S. R. Bordenstein, J. L. Quinn, T. G. Dinan and J. F. Cryan. (2019). Microbiota and the social brain. Science, 366(6465). doi:10.1126/science.aar2016

53. Stapley, N. W., S. R. Guariglia and K. K. Chadman. (2013). Cued and contextual fear conditioning in BTBR mice is improved with training or atomoxetine. Neurosci Lett, 549, 120-124. doi:10.1016/j.neulet.2013.06.032

54. Tillisch, K., J. Labus, L. Kilpatrick, Z. Jiang, J. Stains, B. Ebrat, D. Guyonnet, S. Legrain-Raspaud, B. Trotin and B. Naliboff. (2013). Consumption of fermented milk product with probiotic modulates brain activity. Gastroenterology, 144(7), 1394-1401. e1394.

55. Tomova, A., V. Husarova, S. Lakatosova, J. Bakos, B. Vlkova, K. Babinska and D. Ostatnikova. (2015). Gastrointestinal microbiota in children with autism in Slovakia. Physiol Behav, 138, 179-187. doi:10.1016/j.physbeh.2014.10.033

56. van de Wouw, M., M. Boehme, T. G. Dinan and J. F. Cryan. (2019). Monocyte mobilisation, microbiota \& mental illness. Brain Behav Immun. doi:10.1016/j.bbi.2019.07.019

57. van de Wouw, M., M. Boehme, J. M. Lyte, N. Wiley, C. Strain, O. O'Sullivan, G. Clarke, C. Stanton, T. G. Dinan and J. F. Cryan. (2018). Short-chain fatty acids: microbial metabolites that alleviate stressinduced brain-gut axis alterations. J Physiol. doi:10.1113/JP276431

58. van de Wouw, M., J. M. Lyte, M. Boehme, M. Sichetti, G. Moloney, M. S. Goodson, N. KelleyLoughnane, T. G. Dinan, G. Clarke and J. F. Cryan. (2019). The Role of the Microbiota in Acute StressInduced Myeloid Immune Cell Trafficking. Brain, Behavior, and Immunity. doi:https://doi.org/10.1016/j.bbi.2019.12.003

59. Van de Wouw, M., A. M. Walsh, F. Crispie, L. van Leuven, J. M. Lyte, M. Boehme, G. Clarke, T. G. Dinan, P. Cotter and J. F. Cryan. (Unpublished). Distinct Actions of the Fermented Beverage Kefir on Host Behaviour, Immunity and Microbiome Gut-Brain Modules in the Mouse.

60. Vargas, D. L., C. Nascimbene, C. Krishnan, A. W. Zimmerman and C. A. Pardo. (2005). Neuroglial activation and neuroinflammation in the brain of patients with autism. Ann Neurol, 57(1), 67-81. 
doi:10.1002/ana.20315

61. Vuong, H. E. and E. Y. Hsiao. (2017). Emerging Roles for the Gut Microbiome in Autism Spectrum Disorder. Biol Psychiatry, 81(5), 411-423. doi:10.1016/j.biopsych.2016.08.024

62. Walsh, A. M., F. Crispie, K. Kilcawley, O. O'Sullivan, M. G. O'Sullivan, M. J. Claesson and P. D. Cotter. (2016). Microbial Succession and Flavor Production in the Fermented Dairy Beverage Kefir. mSystems, 1(5), e00052-00016.

63. Zhang, Y., D. Gao, K. Kluetzman, A. Mendoza, V. J. Bolivar, A. Reilly, J. K. Jolly and D. A. Lawrence. (2013). The maternal autoimmune environment affects the social behavior of offspring. $J$ Neuroimmunol, 258(1-2), 51-60. doi:10.1016/j.jneuroim.2013.02.019

\section{Figures}

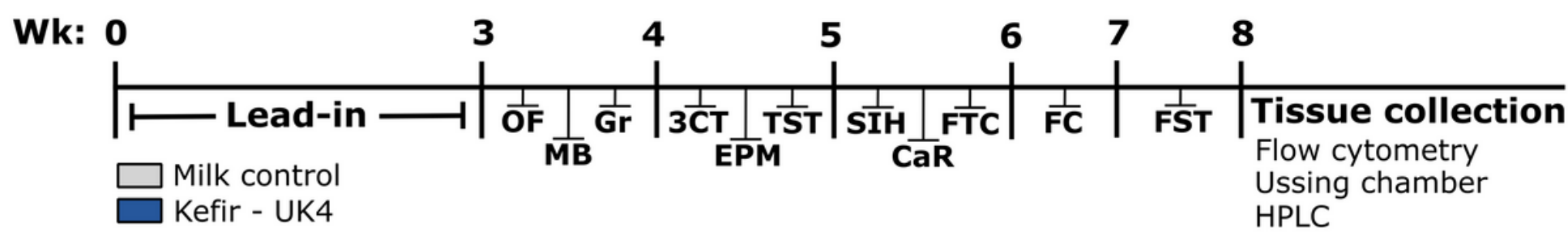

\section{Figure 1}

Experimental design. After one week of treatment lead-in, animals were assessed for their behavioural phenotype. Treatment groups consisted of: Milk control $(n=11)$ Kefir - UK4 $(n=9)$. The order of behavioural tests was as following; Week 3: Open field test (OF), Marble burying test (MB), Grooming test (Gr); Week 4: 3-Chamber social interaction test (3CT), Elevate plus maze (EPM), Tail suspension test (TST); Week 5: Stress-induced hyperthermia test (SIH), Carmine red intestinal motility test (CaR), FITCDextran intestinal permeability test (FTC); Week 6: Fear conditioning (FC); Week 7: Forced swim test (FST); Week 8: Postmortem, the immune system was assessed by flow cytometry, ex vivo intestinal permeability was tested on ileal and colonic tissue using ussing chambers, and ileum and colonic serotonergic levels were quantified by high-performance liquid chromatography (HPLC). 
$\boldsymbol{A}$

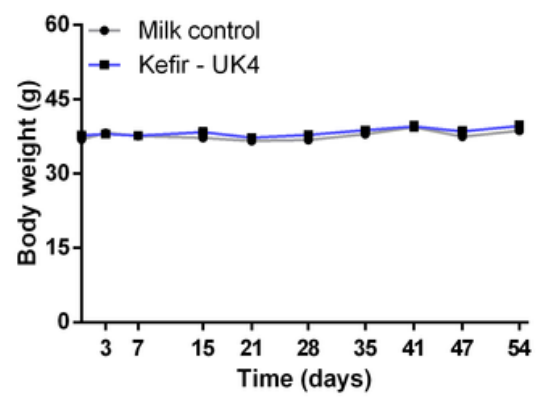

$D$

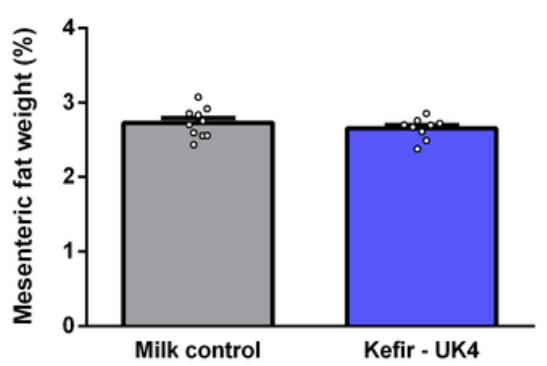

B

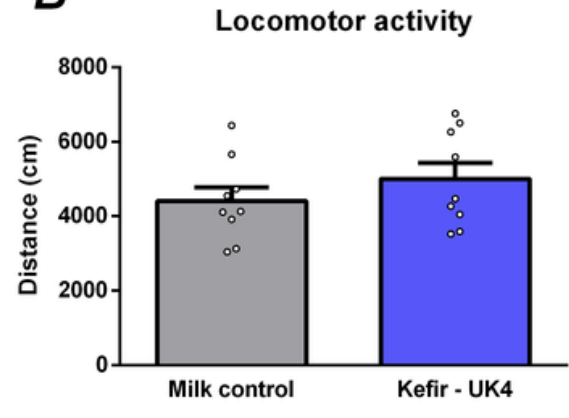

E

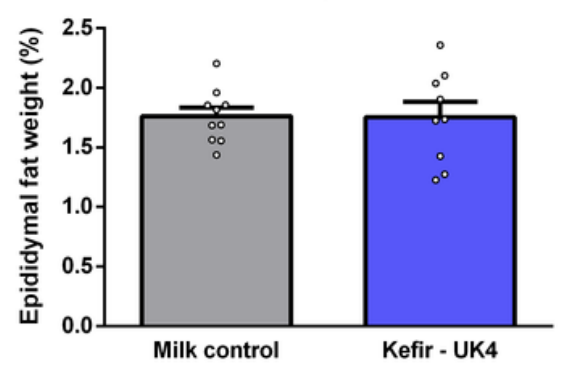

C

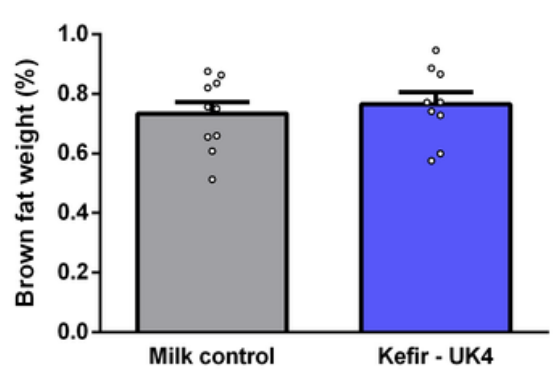

$F \quad$ Subcutaneous fat

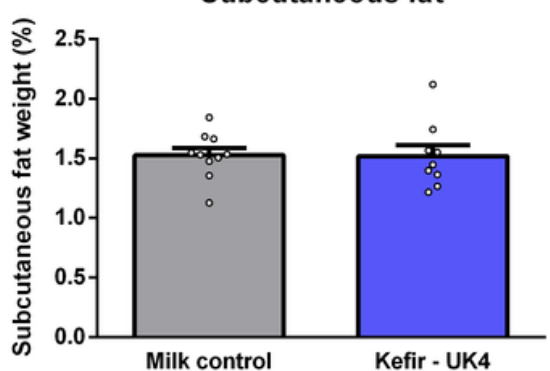

Figure 2

Kefir was well-tolerated. Body weight as measured throughout the study (A). Locomotor activity was assessed in the open field test (B). The different adipose deposits were weighed at the end of the study and normalized to the body weight of each animal. All data are expressed as mean \pm SEM $(n=11-12)$. Dots on each graph represent individual animals.
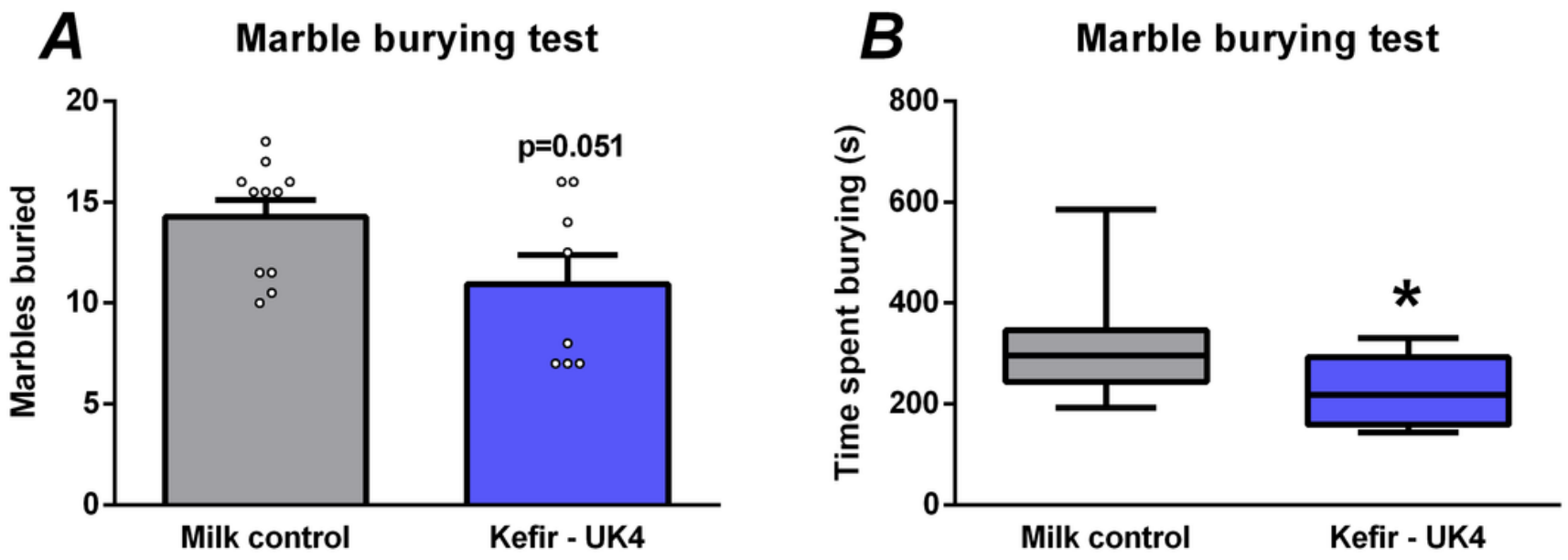

Figure 3

Kefir decreased repetitive behaviour in the marble burying test. Animals were assessed repetitive behaviour using the marble burying test. Both the number of marbles buried was quantified (A), as well as 
the time animals performed burying behaviour (B). The amount of marbles buried was normally distributed and analyzed using an unpaired Student's t-test. The burying time was non-normally distributed and analyzed using the Mann-Whitney U test. Significant differences are depicted as: ${ }^{*} \mathrm{p}<$ 0.05 . All data are expressed as mean \pm SEM or box-plot $(n=8-11)$. Dots on each graph represent individual animals.
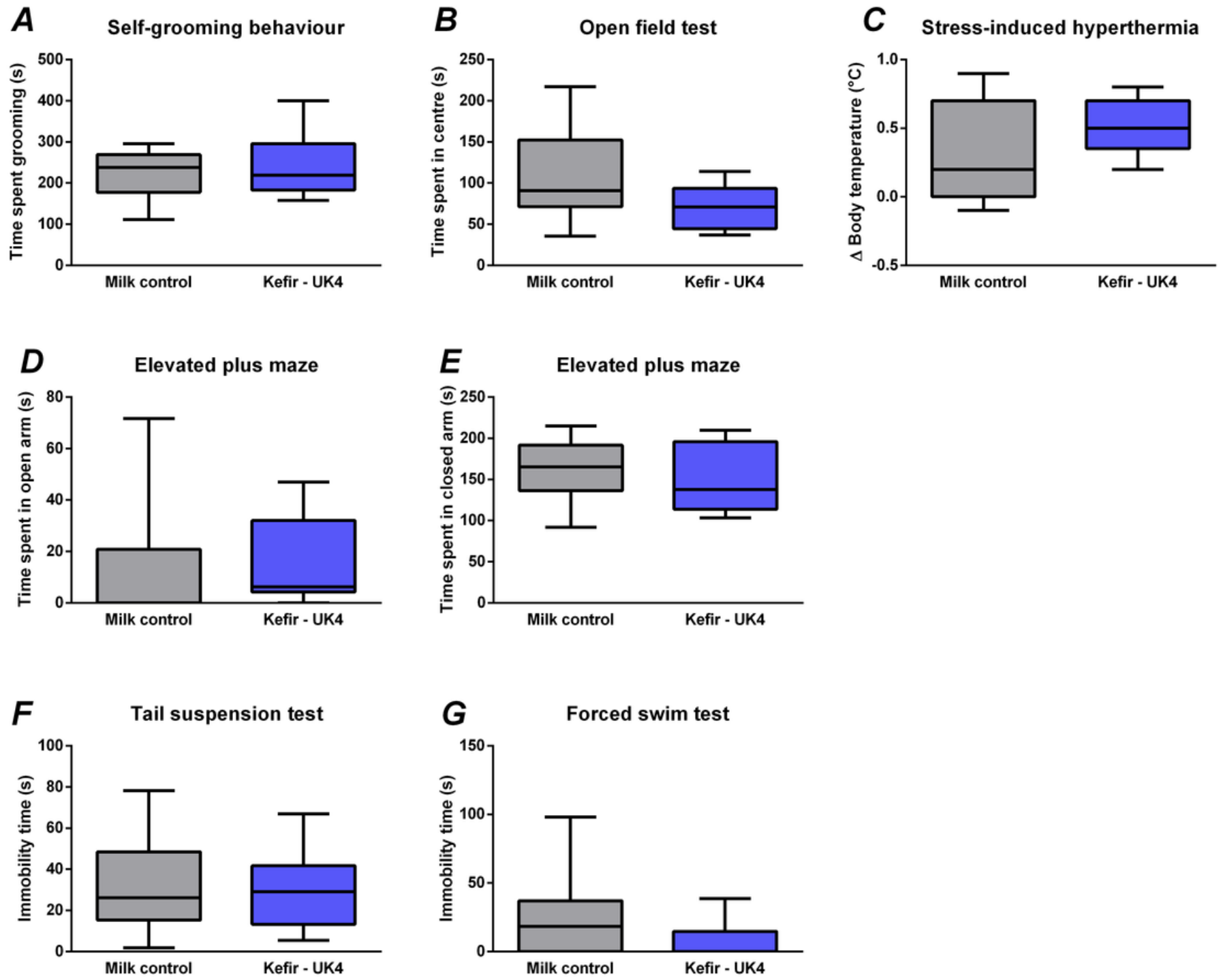

\section{Figure 4}

Kefir did not affect anxiety- and depressive-like behaviour. Animals were assessed for anxiety-like behaviour by quantification of self-grooming behaviour (A), by use of the open field test (B), the stressinduced hyperthermia test (C), and the elevated plus maze (D, E) and. Depressive-like behaviour was determined using the tail suspension test $(\mathrm{F})$ and the forced swim test $(\mathrm{G})$. All data are expressed as boxplots $(n=9-11)$. 

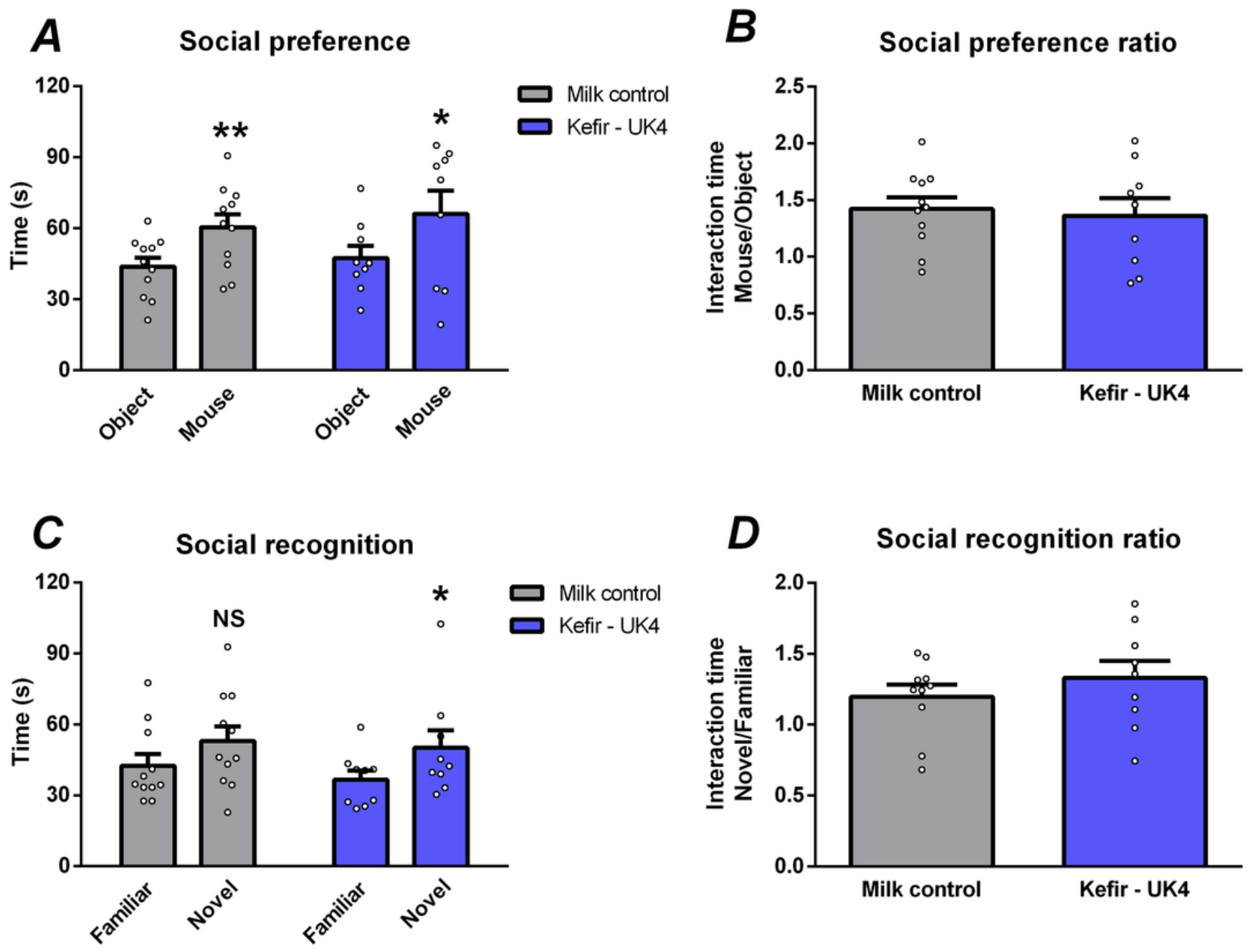

Figure 5

All groups show social preference, while only mice receiving kefir show significant social recognition. Social preference $(A, B)$ and social recognition $(C, D)$ were assessed using the 3 -chamber social interaction test. All data were non-normally distributed and analyzed using the Wilcoxon signed ranks test, except for social preference data for control mice, which were analyzed using a paired Student's ttest. Significant differences are depicted as: ${ }^{*} p<0.05$ and ${ }^{* \star} p<0.01$. Data are expressed as either mean $\pm \operatorname{SEM}(A, B)(n=9-11)$. Dots on each graph represent individual animals. 

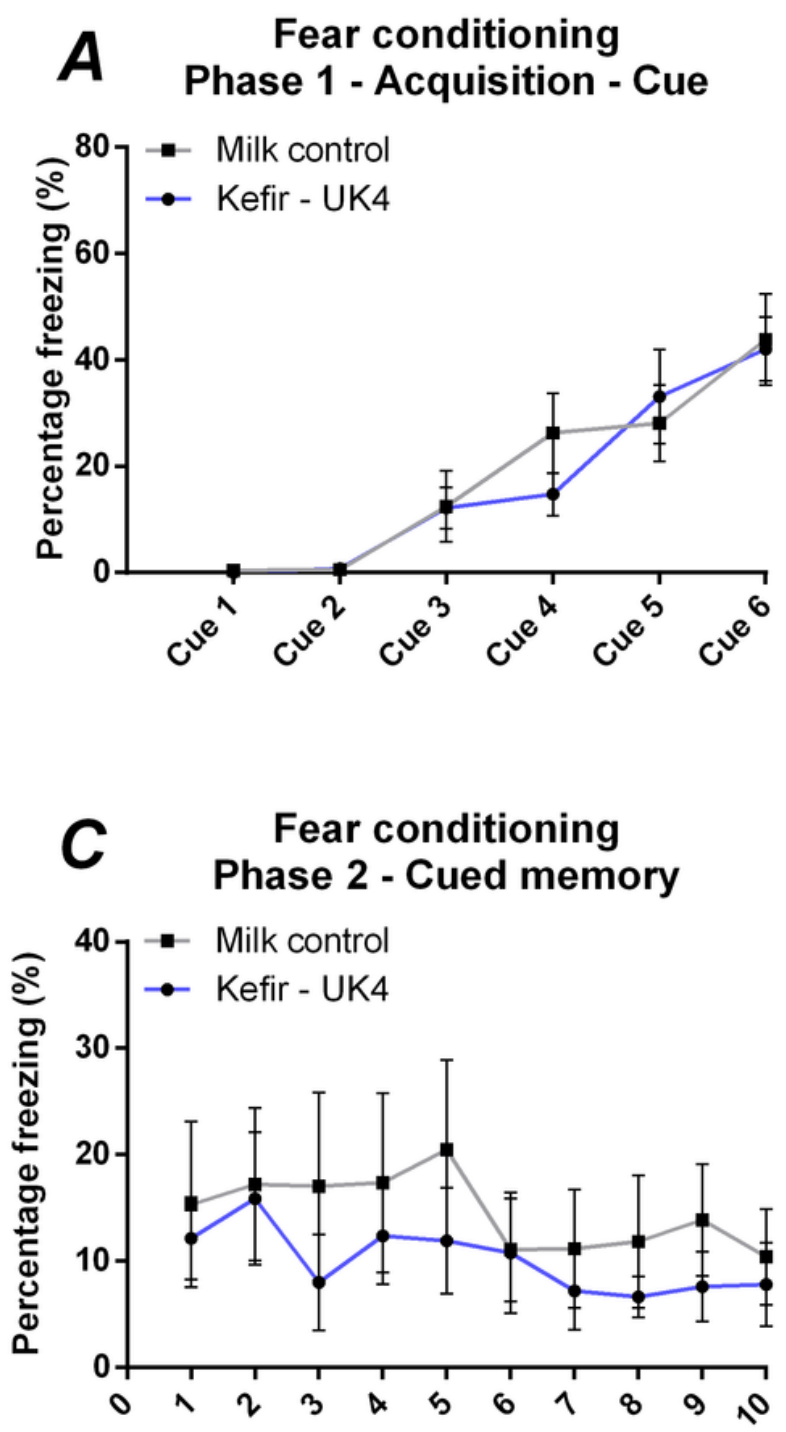

Presentations of the cue
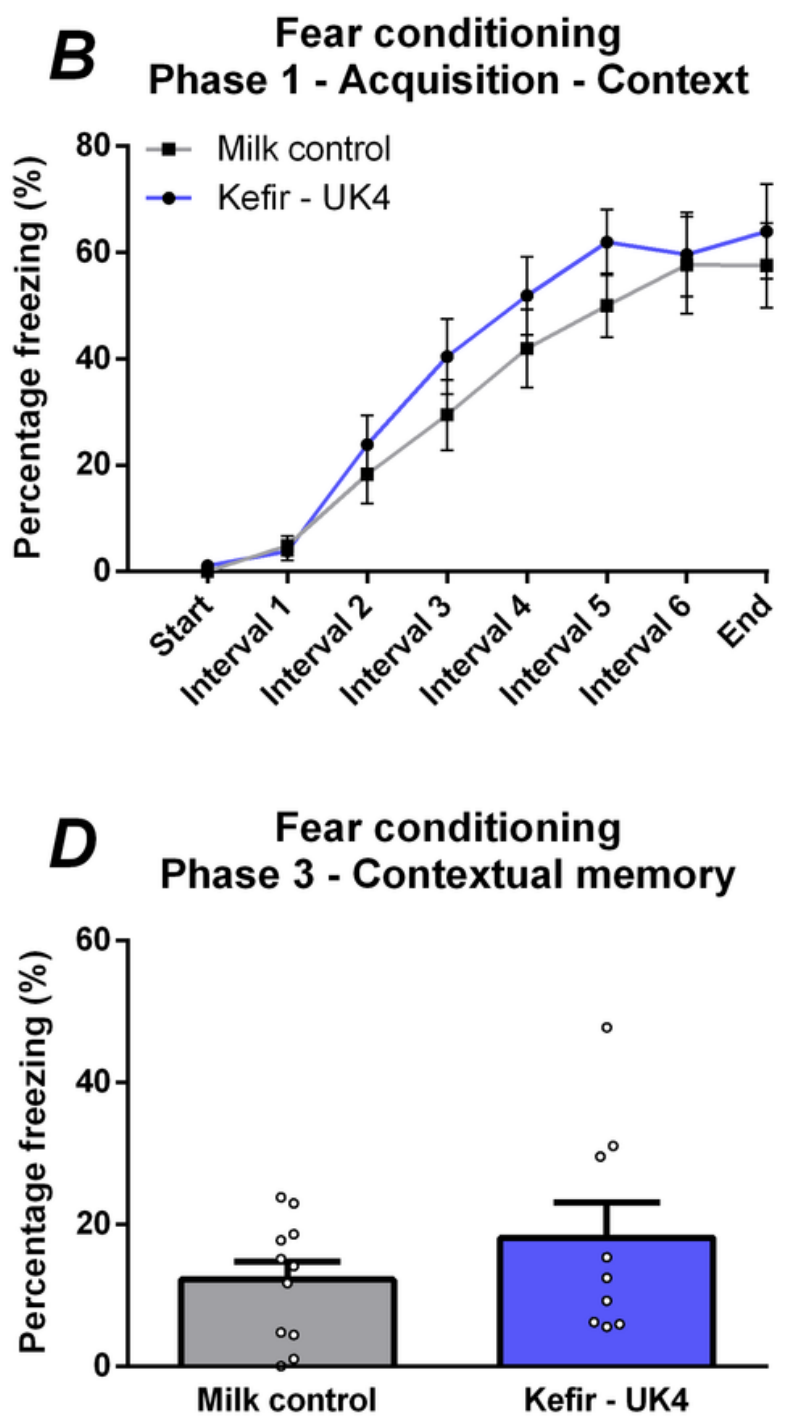

Figure 6

Kefir did not impact fear-dependent cued or contextual memory. Fear-dependent memory and learning were assessed using fear conditioning. At phase 1 - Acquisition, mice were presented with a tone, followed by a foot shock. Cue-associative learning was assessed by measuring freezing behaviour during the presentation of the tone (A), whereas context-associative learning was determined in-between tones (B). At phase 2 - Cued memory, mice received 40 presentations of the same cue (the first 10 are shown), without foot shock, in a different context, in which fear-dependent cued memory was assessed (C). At phase 3 - Contextual memory, mice were exposed to the same context as day one for 5 minutes and contextual memory was assessed (D). All data are expressed as mean \pm SEM $(n=9-11)$. Dots on each graph represent individual animals. 

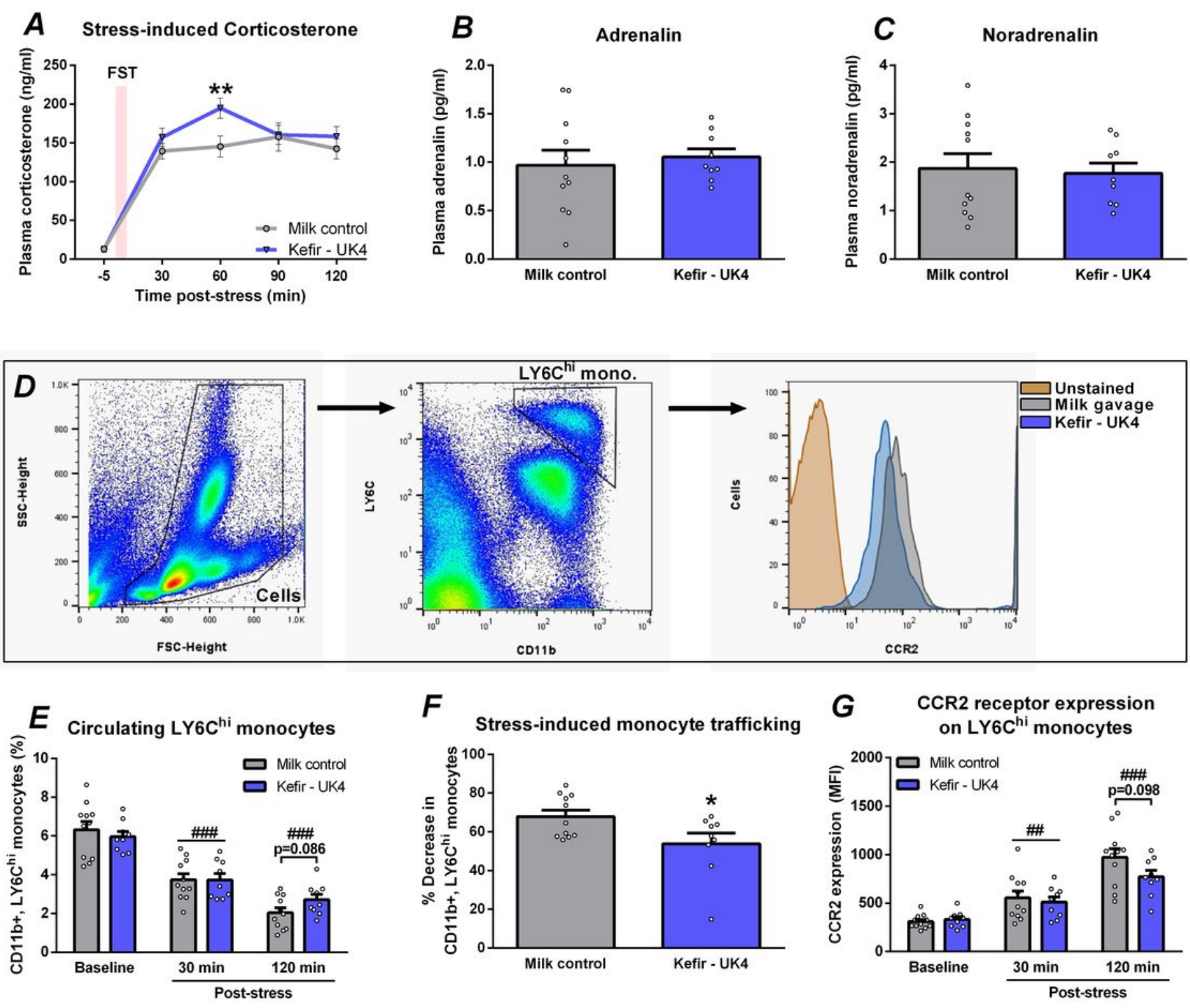

Figure 7

Kefir increases stress-induced corticosterone responses yet decreases LY6Chi monocyte trafficking. Plasma corticosterone levels were quantified before, and after forced swim test stress (A). Adrenalin and noradrenalin levels were quantified from plasma obtained when animals were sacrificed. For flow cytometry, cells were selected based on FSC-height and SSC-height. LY6Chi monocytes were subsequently selected bas on CD11b and LY6C receptor expression, after which CCR2 receptor expression was quantified by assessing median fluorescent intensity (MFI). The histogram plot depicts CCR2 staining intensity of the representative samples of each group 120 minutes post-stress (D). Circulating LY6Chi monocytes (CD11b+, LY6Chi) were quantified at baseline, 30 minutes and 120 minutes post forced swim test stress $(E)$. The relative decrease in LY6Chi monocyte levels were subsequently calculated (F). And CCR2 expression (median fluorescent intensity - MFI) was quantified at baseline, 30 minutes and 120 minutes post-stress. All data were normally distributed. Stress effects were investigated using a one-way ANOVA following Dunnett post hoc correction. Kefir effects were analyzed using an 
unpaired Student's t-test. Significant differences are depicted as: \#\#p $<0.01$ and \#\#\#p $<0.001$ for stress effects; ${ }^{*}<<0.05$ and ${ }^{* *} p<0.01$ for kefir effects. All data are expressed as mean \pm SEM $(n=9-11)$. Dots on each graph represent individual animals.
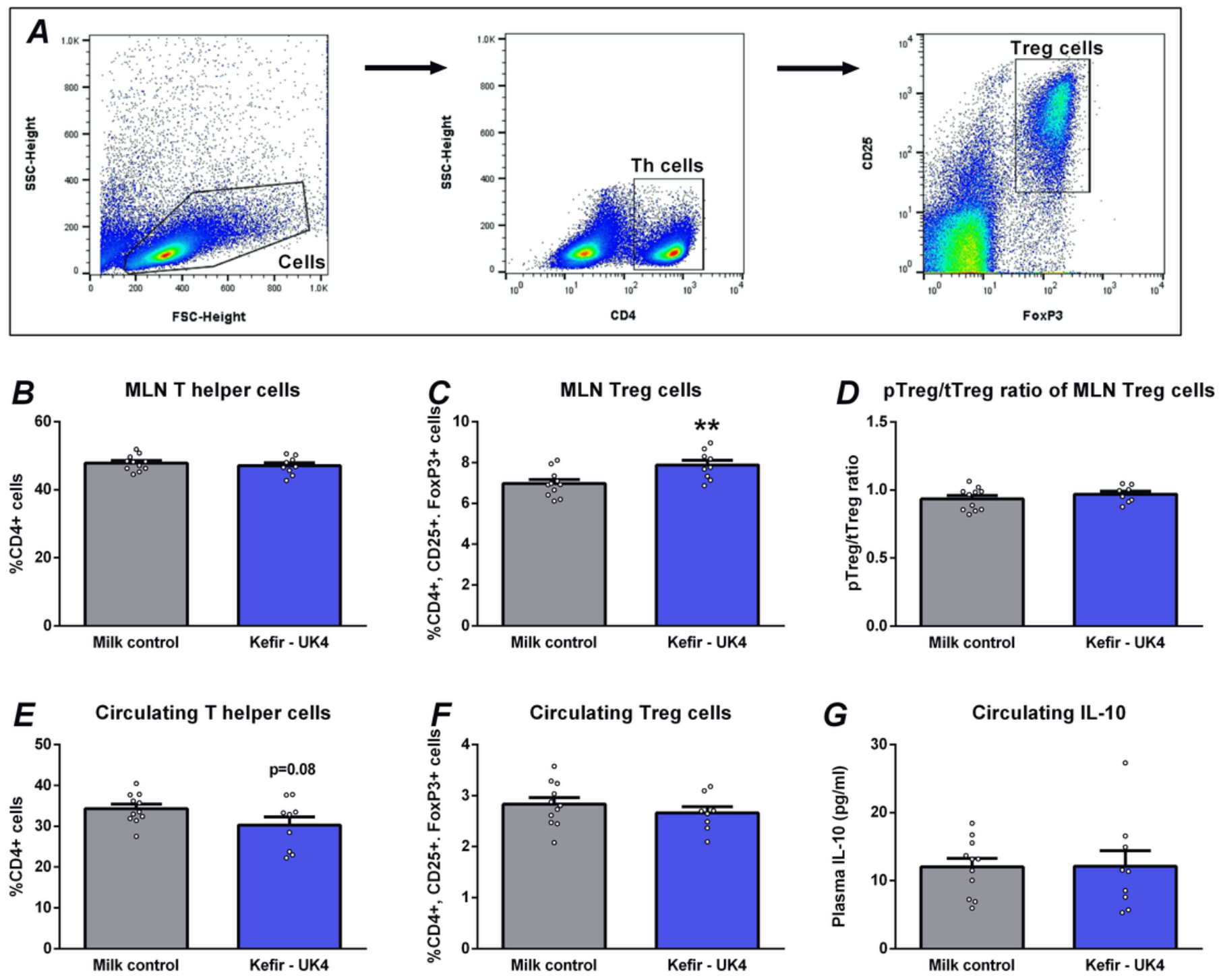

\section{Figure 8}

Kefir increases MLN Treg cell, but not circulating Treg cell levels. Cells were selected based on FSC-height and SSC-height. T helper cells were subsequently selected based on CD4 receptor expressions and Treg cells finally were selected on CD25 receptor expression and FoxP3 transcription factor expression (A). T helper cells (CD4+) were quantified in mesenteric lymph nodes (MLNs) (B). In addition, Treg cell (CD4+, $\mathrm{CD} 25+$, FoxP3+) levels were quantified in MLNs (C). The origin (thymus vs periphery) of Treg cells were subsequently assessed by quantifying the expression of the transcription factor Helios (D). The same analyses were done for blood (E-G). All data were normally distributed and analyzed using an unpaired Student's t-test. Significant differences are depicted as: ${ }^{*} \mathrm{p} p 0.01$. All data are expressed as mean \pm SEM $(n=9-11)$. Dots on each graph represent individual animals. 


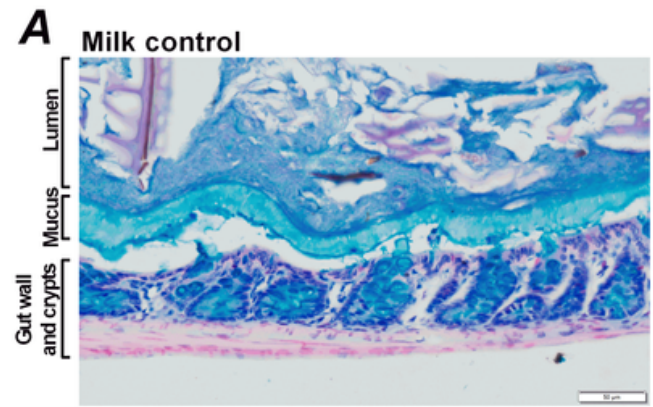

Kefir - UK4
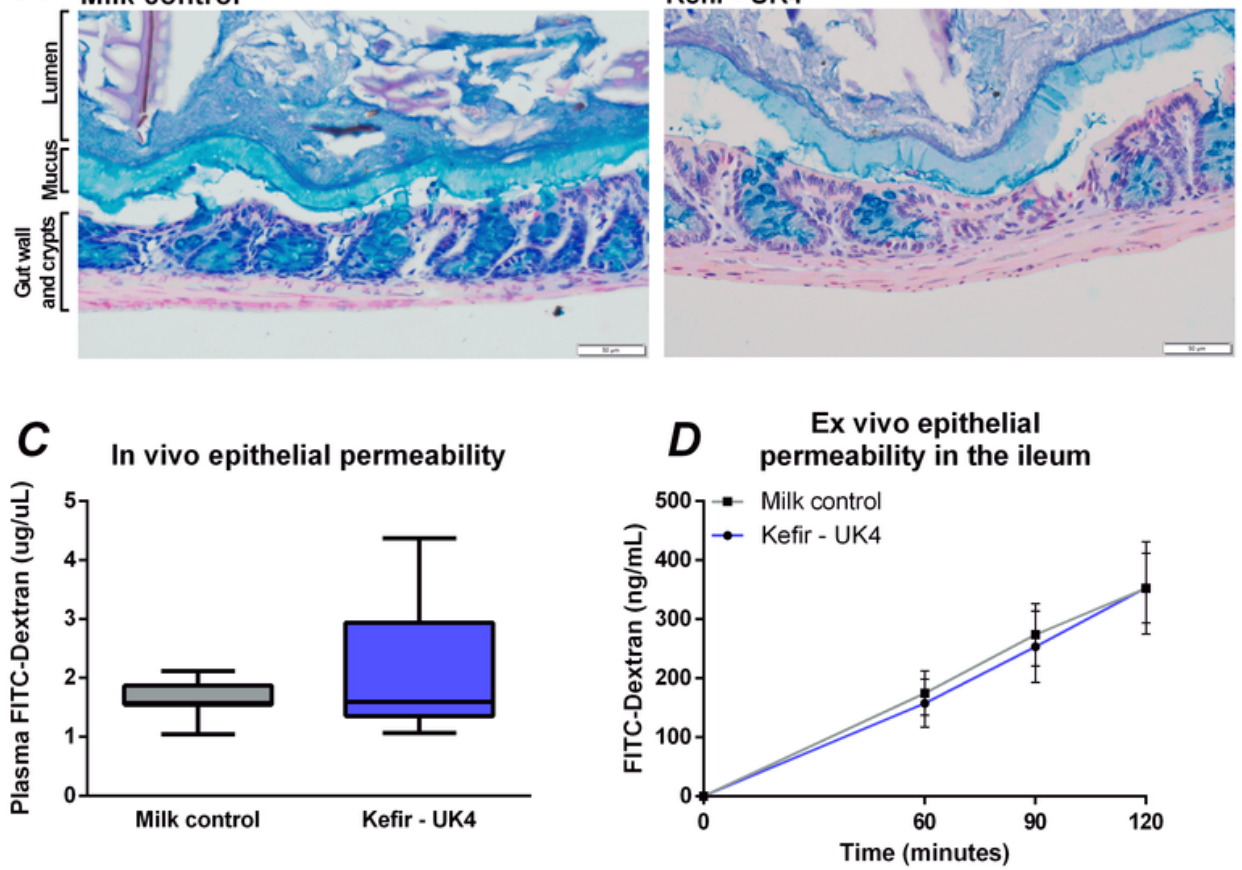
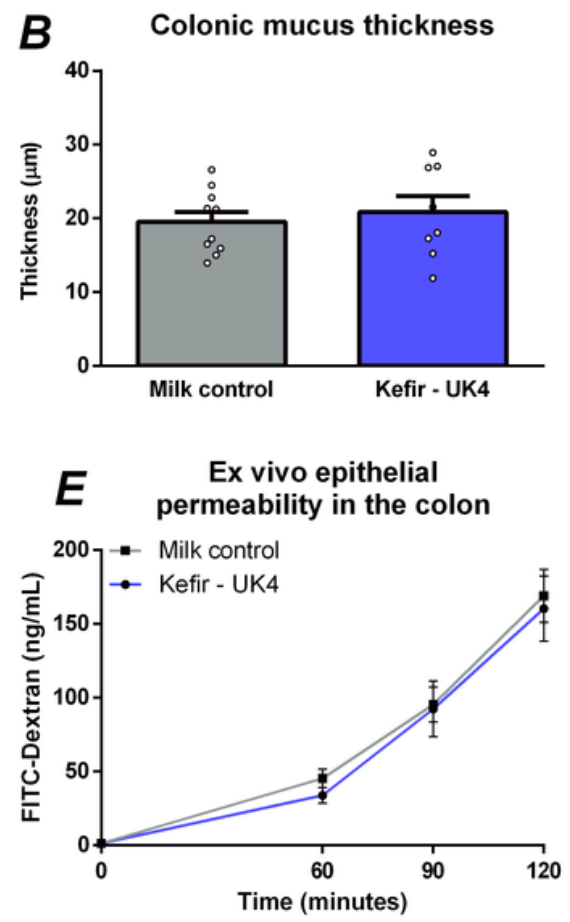

Figure 9

Kefir does not influence colonic mucus thickness or intestinal permeability. Colonic mucus thickness was assessed using alcian blue, periodic acid and Schiff's reagent staining, combined with nuclear fast red staining to stain for cell nuclei (A, B). Intestinal permeability in vivo was assessed by administration of FITC-dextran, followed by tail-tip and subsequent quantification of FITC-dextran in blood plasma (C). Ex vivo permeability of the ileum and colon was investigated using ussing chambers $(D, E)$. All data are expressed as mean \pm SEM or box-plot $(n=8-11)$. 

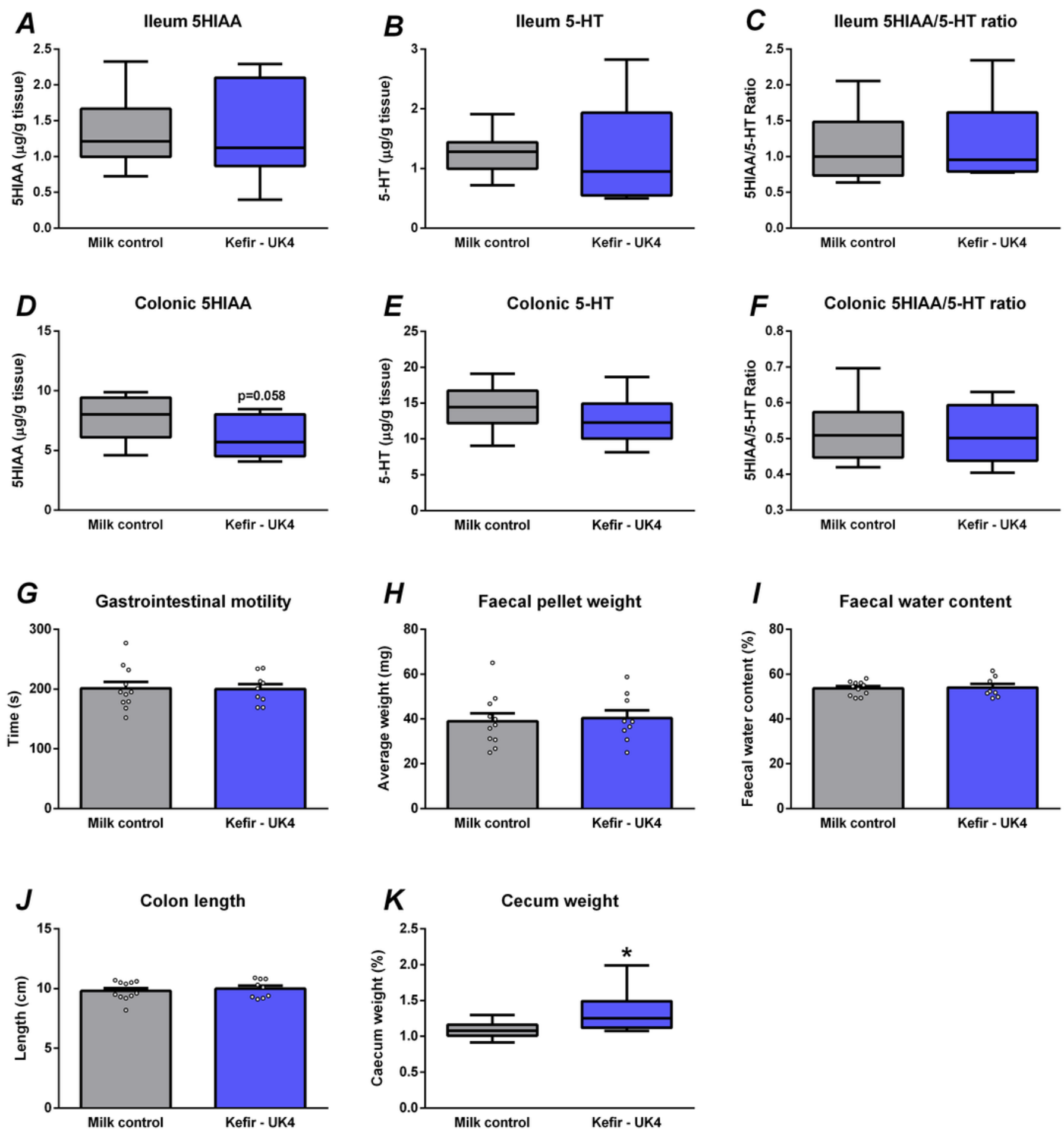

\section{Figure 10}

Kefir does not modulate gut serotonin levels and gastrointestinal motility but does increase caecum size. Ileal (A-C) and colonic (D-F) tissues were quantified for 5HIAA and serotonin (5-HT) levels using HPLC. The $5 \mathrm{HIAA} / 5-\mathrm{HT}$ ratio was subsequently calculated. Gastrointestinal motility was assessed by carmine red administration (G). Faecal pellet weight and water content were quantified during the "faecal water content assessment" $(\mathrm{H}, \mathrm{I})$. Colon lengths and cecum sizes were measured at the end of the study post- 
mortem $(J, K)$. All data are expressed as box-plots or bar graphs as mean \pm SEM $(n=9-11)$. Dots on each graph represent individual animals. 